\title{
Chapter model systems in heterogeneous catalysis at the atomic level: a personal view
}

\author{
Hans-Joachim Freund ${ }^{1 *}$, Markus Heyde ${ }^{1}$, Helmut Kuhlenbeck ${ }^{1}$, Niklas Nilius ${ }^{2}$, Thomas Risse ${ }^{3}$, \\ Thomas Schmidt ${ }^{1}$, Shamil Shaikhutdinov ${ }^{1} \&$ Martin Sterrer $^{4}$ \\ ${ }^{1}$ Fritz Haber Institute of the Max Planck Society, Faradayweg 4-6, Berlin D-14195, Germany; \\ ${ }^{2}$ Fakultät V-Mathematik und Naturwissenschaften, Carl von Ossietzky Universität Oldenburg, Germany; \\ ${ }^{3}$ Institut für Chemie und Biochemie, Freie Universität, Berlin, Germany; \\ ${ }^{4}$ Institute of Physics, University of Graz, Graz, Austria
}

Received November 22, 2019; accepted December 24, 2019; published online March 13, 2020

\begin{abstract}
The review presents an overview of studies in the surface science of oxide and related surfaces with an emphasis of the studies performed in the authors' group. Novel instruments and technique developments, as well as their applications are reported, in an attempt to cover studies on model systems of increasing complexity, including some of the key ingredients of an industrially applied heterogeneous catalyst and its fabrication. The review is intended to demonstrate the power of model studies in understanding heterogeneous catalysis at the atomic level. The studies include those on supported nano-particles, both, prepared in vacuum and from solution, interaction of surfaces and the underlying bulk with molecules from the gas phase, strong metal support interaction, as well as the first attempt to include studies on reactions in confined spaces.
\end{abstract}

model catalysts, oxide surfaces, structure and spectroscopy, supported nanoparticles, reactions in the confined space

Citation: Freund HJ, Heyde M, Kuhlenbeck H, Nilius N, Risse T, Schmidt T, Shaikhutdinov S, Sterrer M. Chapter model systems in heterogeneous catalysis at the atomic level: a personal view. Sci China Chem, 2020, 63: 426-447, https://doi.org/10.1007/s11426-019-9671-0

\section{Introduction}

Heterogeneous catalysts are multi-component, complex materials, which allows us to produce, at the industrial scale, many important chemicals, thus fostering our societal wellbeing [1]. Phenomenologically, heterogeneous catalysis is well understood and well controlled. However, when it comes to understanding the basics of the phenomenon, we are still in the sciences at a stage where we currently lack all the necessary tools to investigate a working catalyst at the atomic level [2,3]. Take one of the most important reactions in heterogeneous catalysis, i.e., the ammonia synthesis, as an example. After Haber, together with Le Rossignol [4], provided the fundamental knowledge, and Bosch/Mittasch [5]

*Corresponding author (email: freund@fhi-berlin.mpg.de) contributed the technical know-how to build an industrial plant, ammonia was available in large quantities, only a few years after the invention. In 1975, Paul Emmett within a Battelle Colloqium on "The Physical Basis of Heterogeneous Catalysis" mentioned: "The experimental work of the past fifty years leads to the conclusion that the rate determining step in ammonia synthesis is the chemisorption of nitrogen. The question as to whether the nitrogen species is molecular or atomic is still not conclusively resolved." [6] This problem was solved through the work of Ertl [7], who showed that nitrogen has to dissociate on an $\mathrm{Fe}(111)$ single crystal before the adsorbed nitrogen atoms are hydrogenated to form ammonia. He used a surface science approach under ultrahigh vacuum conditions on a model surface, i.e., $\mathrm{Fe}(111)$, considerably less complex than Mittasch's ammonia catalyst [8] based on iron promoted by a number of other compo- 
nents. Of course, even so, questions remained: the model surface really representing the catalyst; the observation under ultrahigh vacuum conditions representative for the working conditions of the catalyst at high pressure? The scientific community in the science of catalysis is still working in this direction to answer those questions by increasing the complexity of model systems [9], and developing experiments that allow us to study those systems under working conditions and yet at the atomic scale [10]. The present review is an attempt to highlight some of the progress made by concentrating on the material aspect and the development of instrumentation to answer specific questions from the view points of the authors, rather than covering the entire range of catalytic model studies.

Figure 1 shows the range of model systems we are planning to cover $[11,12]$. Metal single crystals, as briefly mentioned above represent the beginning, followed by welldefined compound-based systems. Here we introduce a novel concept, as we are using thin compound films epitaxially grown on top of metal single crystals. This is an important approach, as it allows to also investigate insulating materials, such as the important oxides, which are often used as support materials in heterogeneous catalysts. In those cases, the traditional surface science techniques based on charged information carriers, such as electrons and ions, may be employed without having to deal with enormous charging problems occurring for bulk materials. Via the control of the thickness of the films, one is in a position to secure that the electronic properties of the films approach those of the bulk materials. The controllable preparation of such supports is an important prerequisite to continue to work towards the next step of complexity by depositing metal nano-particles onto these supports. With this approach, we are in the position to go another step beyond the investigation of metal single crystals as models for the metal particles in supported catalysts, realizing that the electronic properties of small metal particles in the nano-regime are considerably different from bulk metal single crystals due to the size constraints. In ad-

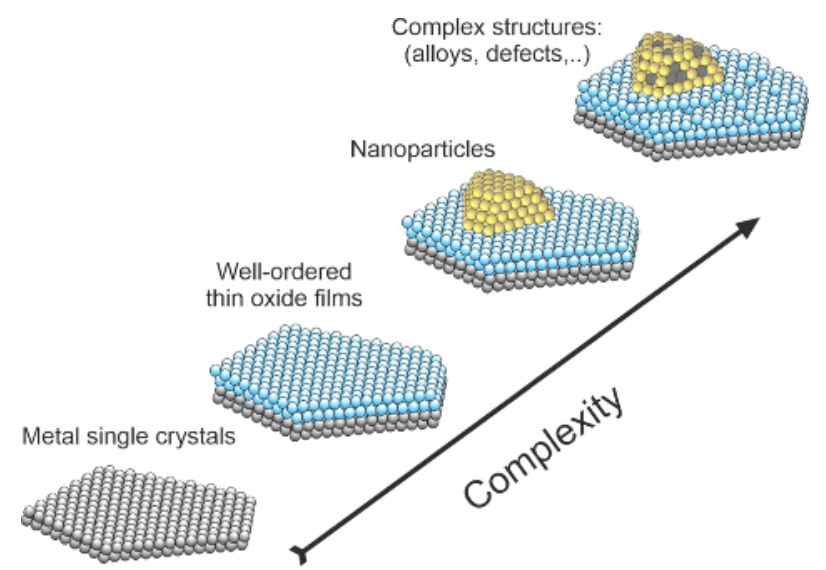

Figure 1 Schematic representation of complexity levels in modelling heterogeneous catalysts (color online). dition, with the preparation of supported particle systems it is possible to address questions concerning the properties of the metal-support interface, and its importance in catalytic reactions, as well as the chance to investigate those phenomena at the atomic level. Even as complex phenomena as the socalled strong metal support interaction (SMSI), involving the encapsulation of metal nano-particles by the support material may be addressed, indicating that we may be able to approach a degree of complexity that captures most of the relevant aspects determining the properties of the "real" catalysts [13].

Model systems prepared along those ideas lend themselves directly to basically all experimental techniques established within the area of surface science under ultrahigh vacuum conditions [14]. This puts us in the position to investigate the properties quantitatively with respect to structures at the atomic level, and to investigate the exposure to a well-defined gas phase. The latter also includes the application of the recently developed near ambient pressure X-ray photoelectron spectroscopy (NAP-XPS) reaching the mbar pressure range, as well as synchrotron-based X-ray absorption techniques to study the influence of pressure on the chemical reactivity [10]. Very recently, it has been demonstrated by Libuda and his group [15], that those model systems may be even taken into the regime of electrochemical and electrocatalytic phenomena. They showed that the systems may be transferred from ultrahigh vacuum into an electrochemical environment, subjected to reactions, and transferred back into ultrahigh vacuum, to investigate the changes that had occurred. We consider this a particularly interesting development for so-called operando ("under working condition") studies. The latter, however, is not subject of the present review. Instead, we will concentrate on the material and characterization aspect of the problem. This involves both instrument developments and the creation of suitable model systems to study various aspects in catalysis.

\section{Instrument development}

In addition to the existing arsenal of surface science tools, including scanning probe microscopy [16,17], electron spectroscopy [18] in ultrahigh vacuum (UHV) and in particular under ambient conditions, instrument developments need to proceed along various lines: we should be able to image the materials, possibly along with the quantitative elemental analysis and electronic property evaluation. We need to perform very surface-sensitive spectroscopy providing chemical and structural information. Since intermediates in chemical reactions may be radicals it would be desirable to develop electron spin resonance (ESR) as a technique applicable to model systems. The following section concentrates on some specific contributions from the 
authors' laboratory.

A low energy electron microscope/photoemission electron microscope (LEEM/PEEM) has been developed over the last 15 to 20 years by a sizable consortium [19-21], providing insitu images (LEEM) and local chemical composition (PEEM) of model systems at about $2.6 \mathrm{~nm}$ spatial resolution in LEEM [20] and about $18 \mathrm{~nm}$ spatial resolution in PEEM [22]. The instrument is depicted in Figure 2, and it is located at the BESSY II synchrotron light source of the Helmholtz Center Berlin (HZB). The magnetic beam splitter allows to expose the sample to photons from the synchrotron light source, as well as electrons produced by an electron gun. The photoemitted or backscattered electrons are guided into an aberration corrector (tetrode mirror for spherical and chromatic aberration correction), then energy analyzed via an omega filter and finally imaged onto a two-dimensional detector. It has been found, that space charge effects, due to the high electron density in the electron plum upon photoemission causes a decrease in resolution in PEEM as compared with LEEM. Modifications are under way to upgrade the resolution via constraining the number of electrons accepted into the beam splitter and tetrode mirror, as discussed by Schmidt et al. [22].

We have developed ESR as a technique to interrogate solid surfaces with respect to the presence of unpaired spins in the surface and on adsorbates [23]. Figure 3(a) shows the setup operating at X-Band $(10 \mathrm{GHz})$, which combines ESR spectroscopy with infrared spectroscopy (IRRAS; red boxes, Figure 3(a)). The design of the ESR experiment was based on prior work by the Baberschke's group [24].

While it became possible to observe and assign radical species, including color centers at oxide surfaces, we noted a lack of resolution to get deeper insight into surface phenomena. In order to improve on resolution, it was necessary to move to higher magnetic fields (W-band, $94 \mathrm{GHz}$ ). The reduced wavelength of the radiation introduces additional constraints which required to develop an appropriate re-

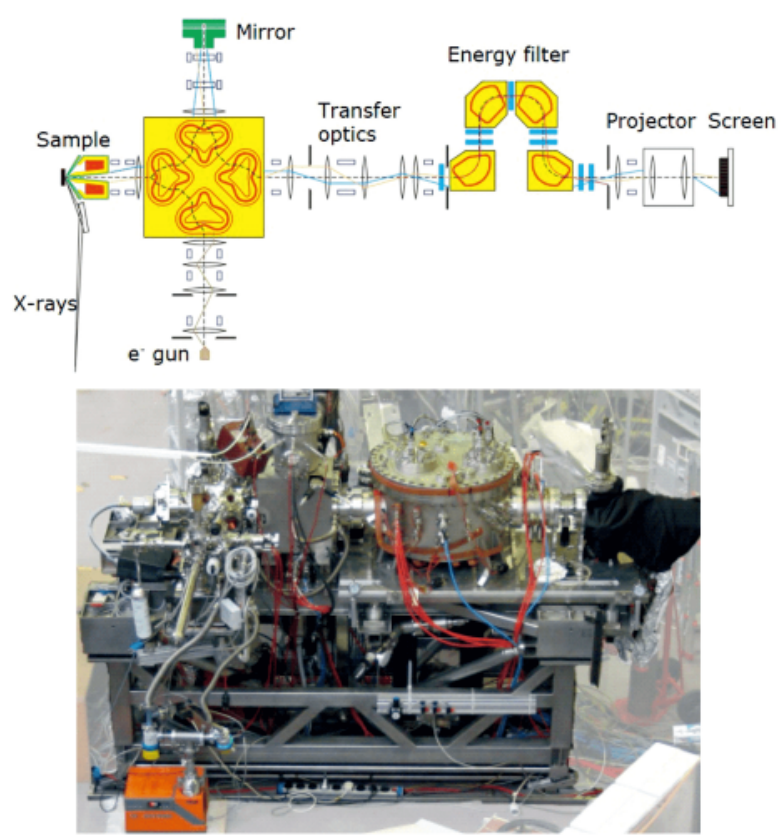

Figure 2 SMART: Spectro-microscope with aberration correction for many relevant techniques, adapted with permission from Ref. [21], copyright by Elsevier (1997) (color online).

sonator structure $[25,26]$. However, it has been possible to set up a working spectrometer (Figure 3(b)) and proving its ability to improve spectral resolution using color centers in oxides as a model system.

A novel technique, called surface action spectroscopy (SAS) has been developed [27,28], which is based on a wellknown approach used in gas phase spectroscopy $[29,30]$. The idea is to attach messengers to a sample, typically a molecule or metal cluster produced in a molecular beam. The sample is irradiated with an intense, tunable light source (for example an infrared free electron laser) to monitor the amount desorbing messengers a function of infrared frequency using a sensitive mass spectrometer. As desorption occurs upon absorption of IR light the flux of desorbing messengers re-
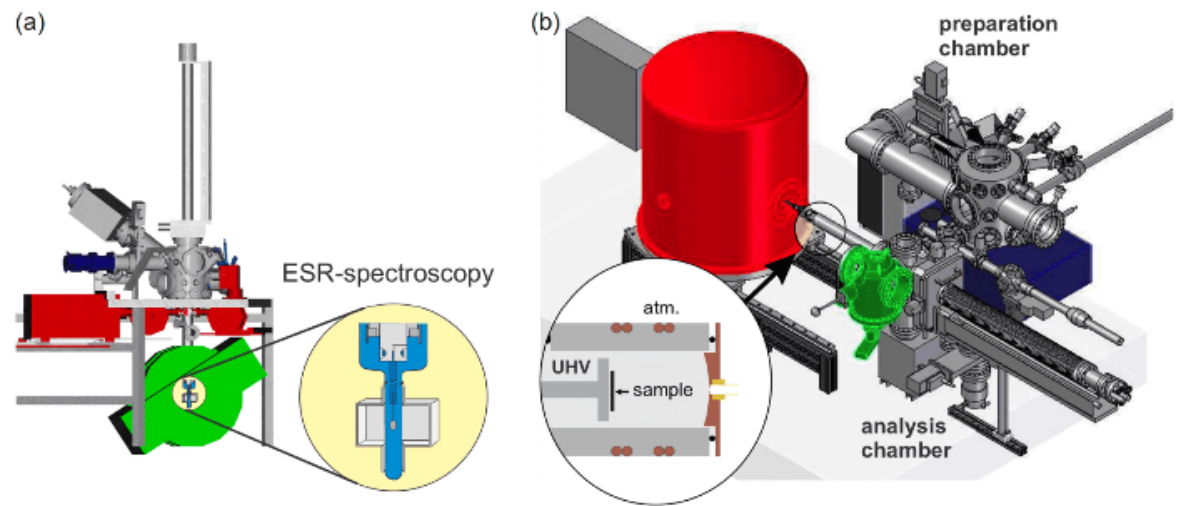

Figure 3 (a) Combined ESR- (X-Band)- and IRA-spectroscopy setup; inset: details of the UHV adaptation using a quartz tube located inside an TE 102 cavity. (b) Experimental setup of the multipurpose W-band ESR apparatus comprising scanning-tunneling (STM) (green) and IRRAS (blue); inset: closeup of the semi-confocal Fabry-resonator using the metal surface as a planar mirror, adapted with permission from Ref. [25], copyright by AIP Publishing (2014), adapted with permission from Ref. [26], copyright by American Physical Society (2016) (color online). 
corded as a function of the light frequency is a vibrational spectrum of the sample. In the gas phase the low density of material produced by a molecular beam renders it impossible to measure a standard infrared absorption spectrum. We transferred this idea to surfaces with the goal to selectively decorate selected areas or species at the surface with messengers, allowing us to record infrared spectra of those features. This requires intense efforts in sample cooling as will be discussed when we come to the presentation of examples. This approach is schematically illustrated in Figure 4, where we show a surface with deposited metal particles, the laser light trajectory, and the mass spectrometer.

The following part of the review on model systems is composed of three sections, covering pure oxide supports as well as oxide supported metal particles, a section on the chemistry on model systems, both including examples towards the application of the techniques briefly mentioned above, and the review ends with some concluding remarks.

\section{Model catalysts}

\subsection{Oxide model supports}

We discuss the structure of two simple metal oxides and two transition metal oxides, in order to elucidate both the ideal structure as well as defects.

Alumina is an important support in heterogeneous catalysis, and it belongs to the class of non-reducible supports. A well-ordered alumina film may be prepared by oxidation of a $\mathrm{NiAl}(110)$ alloy single crystal in UHV, followed by a thermal treatment [31]. The surface of the alumina film is shown in Figure 5(a) as recorded by scanning probe microscopy [32]. The structure is complex, caused by the epitaxy to the support. Its properties resemble those of $\gamma$-alumina, which has also been reported early on by comparison of the phonon spectra [31]. The ideal surface structure indicated in Figure 5 (a) exists next to line defects on the surface, which is indicated by a close up in Figure 5(c) [32]. Those defects play an important role, when it comes to the nucleation of metal atoms to form nano-particles, as we will show below, but they are also important in general when we consider chemical reactivity of oxide surfaces, simply because of the nature of defects with their chemically unsaturated sites. In case of the alumina films on $\mathrm{NiAl}(110)$ another factor determines its properties, i.e., the fact that the films are very thin, and thus cannot completely screen the presence of the metal underneath. It turns out that the possibilities to grow thicker well-ordered films are very limited in this case. This

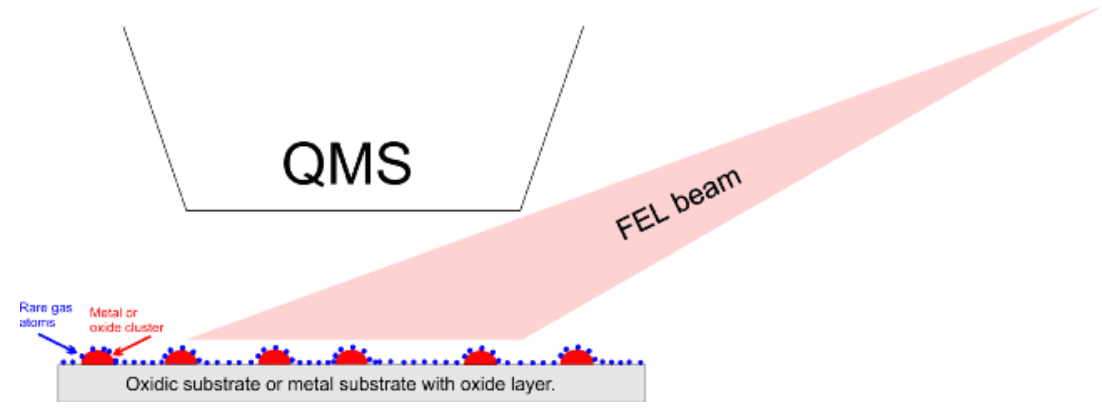

Figure 4 Schematic representation of a surface action spectroscopy experiment. Light from a free electron laser (FEL) is employed to measure a vibrational spectrum of a surface with deposited clusters (color online).
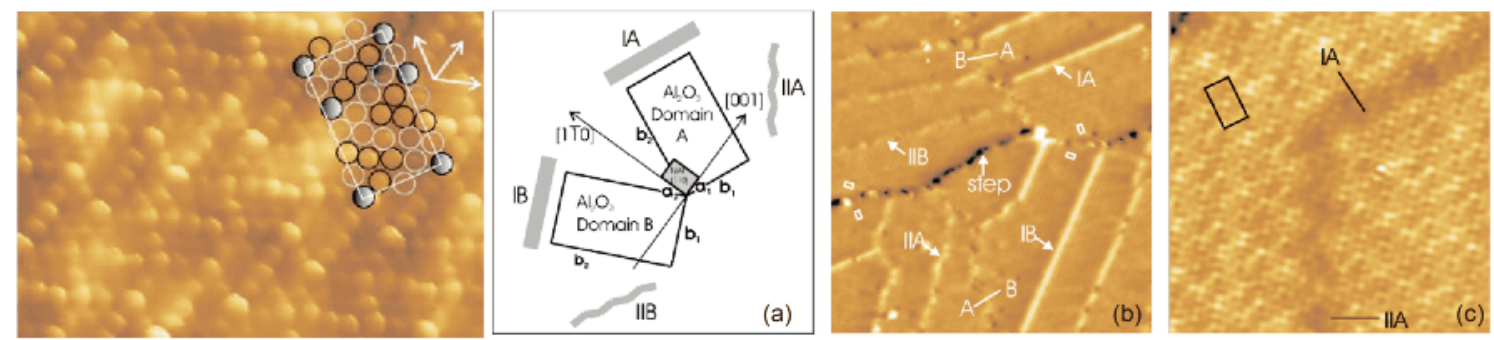

Figure 5 (left) Atomically resolved $\mathrm{STM}$ image of a thin $\mathrm{Al}_{2} \mathrm{O}_{3}$ film on $\mathrm{NiAl}(110)$, taken at $4 \mathrm{~K}$ with $V_{\mathrm{S}}=500 \mathrm{mV}, I_{\mathrm{T}}=1 \mathrm{nA}(58 \AA \times 40 \AA)$. All atoms exhibit a quasihexagonal coordination, where the three characteristic directions are marked with arrows. The unit cell was determined from the repetition of atoms. Here, gray-filled circles mark the most prominent atomic features, thus characterizing six positions of the cell. Furthermore, a zigzagged pattern is observed, where the atoms appear alternately larger and smaller. (right) (a) Dimension of the $\mathrm{Al}_{2} \mathrm{O}_{3}$ unit cell $\left(b_{1}=10.55 \AA, b_{2}=17,89 \AA, \alpha=88.6^{\circ}\right)$ and orientation with respect to the $\mathrm{NiAl}(110)$ substrate $\left(a_{1}=2.89 \AA, a_{2}=4.08 \AA\right)$. The orientation and structure of the antiphase domain boundaries (APDP) is shown schematically (IA, IIA, IB, IIB). (b) Thin alumina film on NiAl(110), imaged at $77 \mathrm{~K}\left(V_{\mathrm{S}}=4.5 \mathrm{~V}, I_{\mathrm{T}}=0.5 \mathrm{nA}, 378 \AA \times 378 \AA\right)$. The $z$-signal was differentiated, and thus both terraces appear on the same height. The size and the orientation of the $\mathrm{Al}_{2} \mathrm{O}_{3}$ unit cell are marked with a white rectangle in each domain. APDB appear as bright lines, where a straight (IA and IB) and a zigzagged (IIA and IIB) type can be distinguished for each domain. In contrast to reflection domain direction boundaries (A-B), each of them runs along a characteristic direction. (c) STM image with higher resolution $\left(V_{\mathrm{S}}=-2.0 \mathrm{~V}, I_{\mathrm{T}}=0.5 \mathrm{nA}, 129 \AA \times 129 \AA\right)$ of a straight (IA) and a zigzagged (IIA) APDB in the A domain, adapted with permission from Ref. [32], copyright by American Physical Society (2001) (color online). 
is one reason, why other oxides have been used more frequently in model studies.

An example is $\mathrm{MgO}$. The structural quality of $\mathrm{MgO}$ films is largely governed by a non-perfect lattice match with the support, which induces interfacial lattice strain that needs to be released by structural distortions in the film. Not surprisingly, relatively smooth and homogenous $\mathrm{MgO}(100)$ films have been grown on $\operatorname{Ag}(001)$ that features only $3 \%$ lattice mismatch with bulk $\mathrm{MgO}$ [33]. The film quality can be further improved by post-annealing these layers at $773 \mathrm{~K}$, followed by a slow cooling-down procedure [34,35]. A scanning-tunneling (STM) image of the film morphology is shown in Figure 6(a), and an atomically resolved image is given in Figure 6(b). The terraces exhibit a perfect arrangement of protrusions in (100) orientation and straight step edges terminating the terraces of the film with a thickness of 3-4 layers (the dark areas represent the open Ag substrate). Under the given tunneling conditions the Mg ions are imaged as bright protrusions. Oxygen vacancies can be stabilized in three charge states on $\mathrm{MgO}(100)$ surfaces that is as neutral $\left(F^{0}\right)$, singly $\left(F^{+}\right)$and doubly charged color centers $\left(F^{2+}\right)$. The latter turned out to be energetically unfavorable in thin films given the quasi infinite electron reservoir of the metal support just below. Figure 6(c) shows an STM image of a $\mathrm{MgO}(100)$ terrace after an oxygen vacancy has been created by the STM tip. The Mg ions, imaged as bright protrusions, are not influenced but there is a dark area in between centered on the oxygen vacancy site, indicating that the vacancy influences its surroundings electronically.

The lattice mismatch on $\mathrm{Mo}(001)$ is considerably larger $(5.3 \%)$ and results in the development of a dense dislocation network to compensate the strain [37].

With increasing oxide thickness, additional defect types develop next to the dislocation network (Figure 7). Prominent defects at $10 \mathrm{ML}$ film thickness are screw and edge dislocations the latter being aligned with the non-polar [100] equivalent directions of $\mathrm{MgO}$ [38]. Also point defects, in particular oxygen vacancies, become more abundant. They

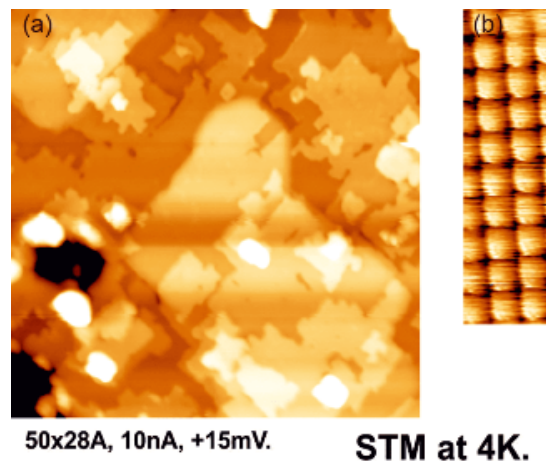

Figure $6 \mathrm{MgO}(100) / \mathrm{Ag}(001)$ system. (a) Low-temperature STM image of $4 \mathrm{ML} \mathrm{MgO}(100) / \mathrm{Ag}(100)(+3.5 \mathrm{~V}, 0.2 \mathrm{nA})$. Atomic resolution STM images of a regular terrace (left; $+0.02 \mathrm{~V}, 3 \mathrm{nA}$ ), without (b) and with a color center defect (c), adapted with permission from Ref. [36], copyright by Springer Nature (2015) (color online).

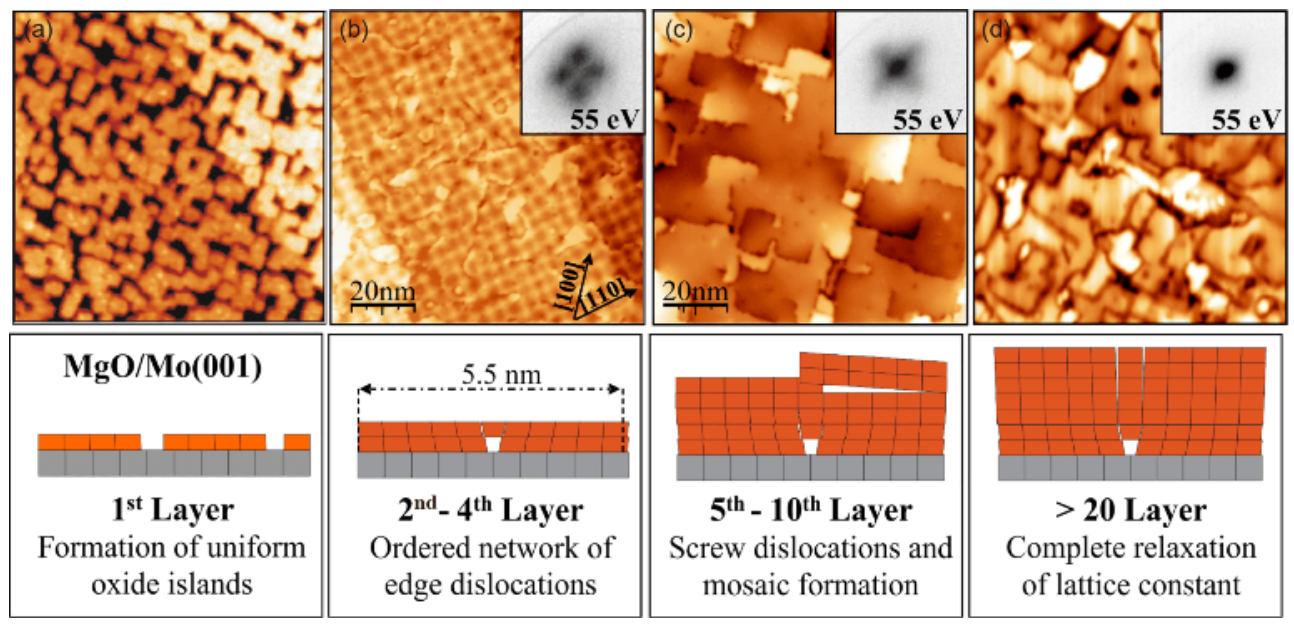

Figure 7 STM images showing several states of strain relaxation in $\mathrm{MgO}$ thin films on a $\mathrm{Mo}(001)$ support $\left(100 \mathrm{~nm} \times 100 \mathrm{~nm}, V_{\mathrm{S}}=4.0 \mathrm{~V}\right)$. (a) Submonolayer coverage with square shaped $\mathrm{MgO}$ islands. Their size is controlled by the interfacial lattice strain. (b) $3 \mathrm{ML}$ thick film displaying a squared coincidence lattice. (c) $7 \mathrm{ML}$ thick film characterized by wide, atomically flat terraces, separated by edge and screw dislocations. (d) $18 \mathrm{ML}$ film with bulk-like lattice parameters. The image quality in (d) is degraded due to the vanishing conductivity of thick MgO layers, adapted with permission from Ref. [36], copyright by Springer Nature (2015) (color online). 
mostly locate along step edges, where the atomic coordination is reduced with respect to atoms embedded in a compact terrace. Recent STM and AFM experiments have proven that the precise charge state of the color centers can be determined on the single-defect level. Whereas STM conductance spectroscopy evaluates the energy position of defect-induced gap states in $\mathrm{MgO}$ [39], AFM probes the electrostatic interactions between the charged defect and the probe tip [40].

Another way of characterizing such color centers is electron spin resonance as it detects unpaired spins. We apply the instrument developed in the group (see above). Figure 8(a) shows angle dependent electron paramagnetic resonance (EPR) spectra of color centers in $\mathrm{MgO}$ [41]. Due to the lower surface Madelung energy they are located in the $\mathrm{MgO}(100)$ top layer. From the angular dependence in conjunction with $g$-tensor modelling the symmetry may be deduced and thus the location of the color center at the edges of the film terraces may be determined, which is consistent with STM/ AFM measurements. The resolution of the spectra may be considerably improved by increasing the magnetic field. Figure 8(b) shows a comparison between X-band (top) and $\mathrm{W}$-band spectra (below) of $\mathrm{MgO}$ color centers located in the bulk of the $\mathrm{MgO}$ film. From a detailed $g$-tensor analysis as well as angle dependent measurements (see Figure 8(c)), we concluded that those species are located at screw dislocations inside the $\mathrm{MgO}$ film [26].

Vanadium oxides play a relevant role in the area of catalysis which triggered a number of studies in the areas of basic and applied research. Many of the reactions involve the transfer of oxygen atoms since vanadium can easily change its oxidation state [43]. Some results are summed up in recent review papers [44-50]. Part of the studies involved catalyst models where well-defined high-quality crystalline surfaces
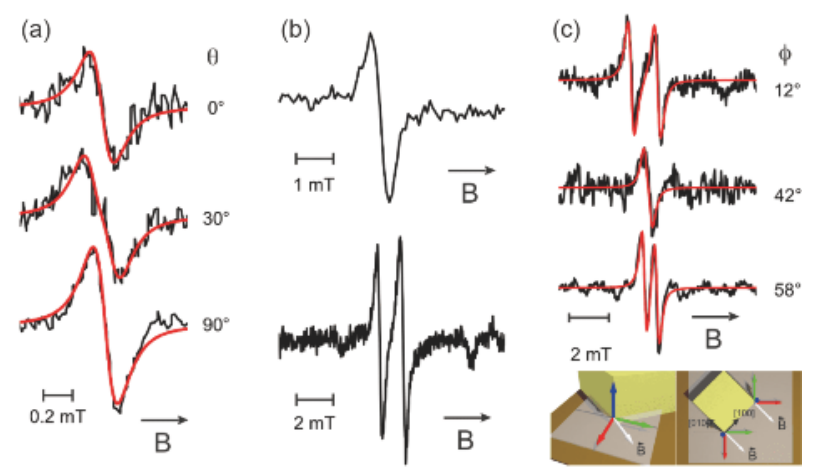

Figure 8 (a) Angle dependent X-band ESR spectra of $\mathrm{F}^{+}$-centers on $\mathrm{MgO}$ (100) surface, adapted with permission from Ref. [38], copyright by American Physical Society (2008). (b) Top: X-band; bottom: W-band ESR spectra of paramagnetic defects in $\mathrm{MgO}$ films, adapted with permission from Ref. [23], copyright by American Physical Society (1995). (c) Angle dependent W-band spectra of Refs. [26,42], adapted with permission from Ref. [26], copyright by American Physical Society (2016), adapted with permission from Ref. [42], copyright by John Wiley and Sons (2011) (color online). are employed, which led to studies where the preparation of ordered thin films was investigated.

Different types of well-ordered thin films have been prepared. There are reports of $\mathrm{V}_{2} \mathrm{O}_{5}(001)$ layers on $\mathrm{Au}(111)$ only, [51,52] whereas $\mathrm{V}_{2} \mathrm{O}_{3}(0001)$ thin films have been grown for a number of substrates: $\mathrm{Au}(111)[53,54], \mathrm{W}(110)$ [55], $\mathrm{Rh}(111)$ [56], $\mathrm{Pd}(111)$ [57], and $\mathrm{Cu}_{3} \mathrm{Au}(100)$ [58]. $\mathrm{VO}_{2}$ (110) has been reported to grow on $\mathrm{TiO}_{2}(110)$ [59] and $\mathrm{SnO}_{2}$ (110) $[60,61]$ but extended adsorption/reaction studies had not been performed.

$\mathrm{V}_{2} \mathrm{O}_{5}(001)$ and $\mathrm{V}_{2} \mathrm{O}_{3}(0001)$ may both be prepared on $\mathrm{Au}$ (111) with the major difference between the preparation recipes being the oxygen pressure during vanadium oxidation: 50 mbar are employed for $\mathrm{V}_{2} \mathrm{O}_{5}(001)[51,52]$ while for $\mathrm{V}_{2} \mathrm{O}_{3}$ (0001) pressures in the $10^{-6}$ mbar range are used [51-55].

Figure 9 shows STM images of $\mathrm{V}_{2} \mathrm{O}_{5}(001)$ layers on $\mathrm{Au}$ (111) [52]. The vanadyl double rows, which terminate regular $\mathrm{V}_{2} \mathrm{O}_{5}(001)$, are clearly recognizable in the right panel of Figure 9. LEED images of $\mathrm{V}_{2} \mathrm{O}_{5}(001)$ layers on $\mathrm{Au}(111)$ exhibit ring-like patterns instead of spots [52] which is attributed to the weak interaction between the oxide overlayer and the $\mathrm{Au}(111)$ substrate. This is probably also the reasons for the different azimuthal orientations of the islands in the left panel of Figure 9. If the oxide coverage is increased, the islands eventually meet, which results in the domain boundaries seen in the center panel [52]. $\mathrm{V}_{2} \mathrm{O}_{3}(0001)$ layers on $\mathrm{Au}(111)$ [53-55] are well ordered but exhibit a somewhat higher density of point defects, see Figure 10(a) [62]. This aspect was investigated in detail since defects may have a significant impact on the catalytic activity.

The lattice structure of $\mathrm{V}_{2} \mathrm{O}_{3}$ is of corundum type and the (0001) surface is the basal plane of this hexagonal lattice. Figure 10(b) shows that the corundum lattice consists of alternating quasi-hexagonal oxygen layers and vanadium double layers along [0001]. According to Tasker's rule [63] the single-metal (SM) termination is the only stable surface structure. It turns out that the actually observed, after some scientific debates $[55,57,64,65]$, and finally accepted structure, is the vanadyl-terminated surface, where an additional oxygen atom is bound to the surface vanadium atom by a characteristic $\mathrm{V}=\mathrm{O}$ double bond.

Surface action spectroscopy, infrared reflection absorption spectroscopy (IRAS) and high resolution electron energy loss spectroscopy (HREELS) spectra of the $\mathrm{V}_{2} \mathrm{O}_{3}(0001)$ film are shown in Figure 10(c) to illustrate how surface action spectroscopy, the novel surface spectroscopy we addressed above, compares to other vibrational spectroscopic techniques. Curve (a) displays the IRAS spectrum which was obtained via dividing the spectrum of the pristine $\mathrm{V}_{2} \mathrm{O}_{3}(0001)$ film, the sample spectrum, by a reference spectrum, which was a spectrum of the $\mathrm{V}_{2} \mathrm{O}_{3}(0001)$ film with the vanadyl oxygen atoms removed by electron bombardment [65]. The reduced film still contains some isolated $\mathrm{V}=\mathrm{O}$ groups on the 


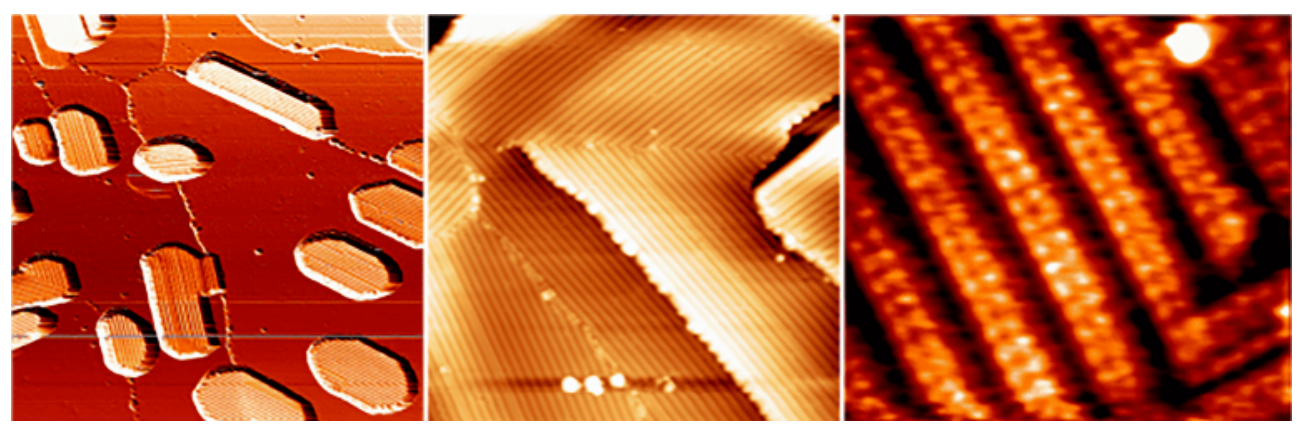

Figure 9 Left: $\mathrm{V}_{2} \mathrm{O}_{5}(001)$ islands on $\mathrm{Au}(111), 100 \mathrm{~nm} \times 100 \mathrm{~nm}, U=3 \mathrm{~V}, I=0.2 \mathrm{nA}$. Center: closed $\mathrm{V}_{2} \mathrm{O}_{5}(001)$ layer, $50 \mathrm{~nm} \times 50 \mathrm{~nm}, U=2 \mathrm{~V}, I=0.2 \mathrm{nA}$. Right: closed $\mathrm{V}_{2} \mathrm{O}_{5}(001)$ layer, $5.8 \mathrm{~nm} \times 6.4 \mathrm{~nm}, U=3.5 \mathrm{~V}, I=0.2 \mathrm{nA}$, adapted with permission from Ref. [51], copyright by American Chemical Society (2008), adapted with permission from Ref. [52], copyright by American Chemical Society (2008) (color online).
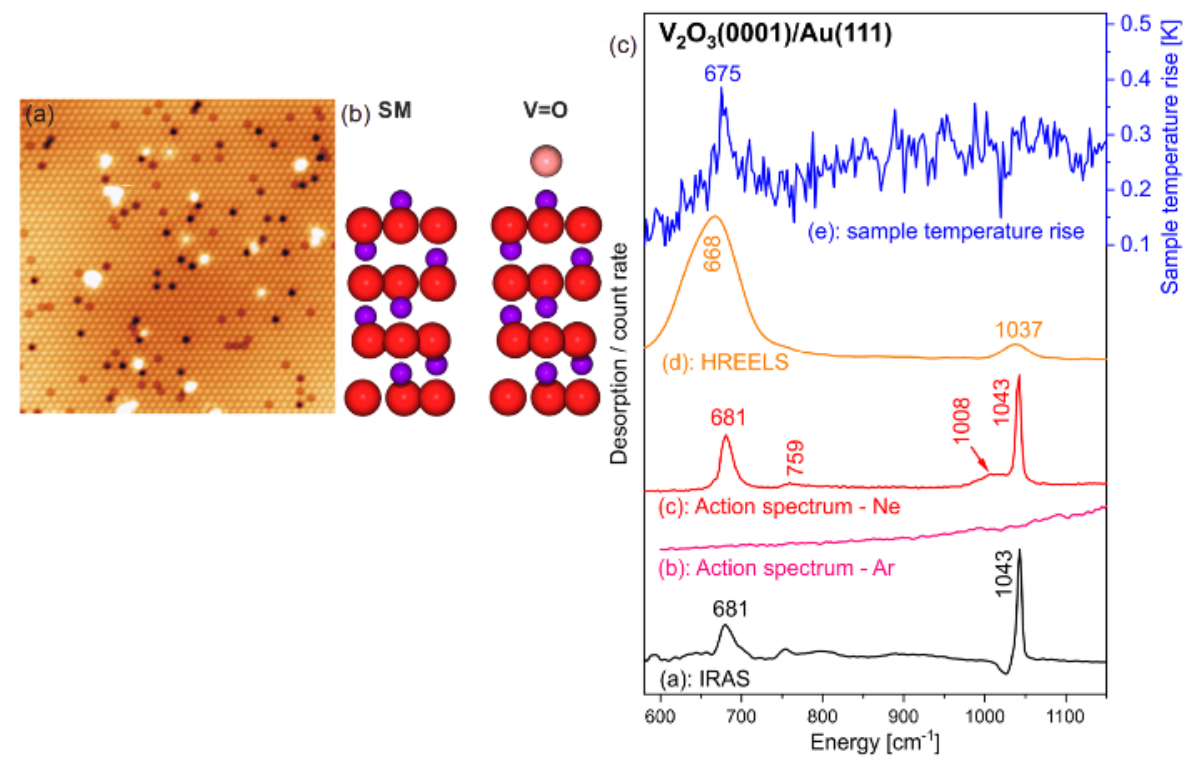

Figure 10 (a) STM image of vanadyl terminated $\mathrm{V}_{2} \mathrm{O}_{3}(0001) / \mathrm{Au}(111), 20 \mathrm{~nm} \times 20 \mathrm{~nm}, U=1.5 \mathrm{~V}, I=0.2 \mathrm{nA}$. (Reprinted with permission from ref. [62], copyright by Springer (2011)). (b) $\mathrm{V}_{2} \mathrm{O}_{3}(0001)$ surface terminations (SM: single metal termination, $\mathrm{V}=\mathrm{O}$ : vanadyl termination). Red: bulk oxygen, light red: vanadyl oxygen, blue: vanadium. Adapted from Ref. [53], copyright (2015) by the American Chemical Society. (c) Comparison of HREELS, IRAS and surface action spectra of $\mathrm{V}_{2} \mathrm{O}_{3}(0001) / \mathrm{Au}(111)$, adapted with permission from Ref. [28] copyright by AIP Publishing (2018) (color online).

surface. The vibration of such isolated $\mathrm{V}=\mathrm{O}$ groups has an energy below $1,040 \mathrm{~cm}^{-1}$ due to the reduced dipole coupling between the $\mathrm{V}=\mathrm{O}$ groups [20]. The remnant vanadyl groups on the reference sample surface cause a negative peak located at $1,020 \mathrm{~cm}^{-1}$ in the IRAS spectrum (curve (a)). The use of reference spectra is a general drawback of infrared spectroscopy. If the reference spectrum contains vibrational features, which is often the case, then these features will be found in the division spectrum with the negative intensity, thereby contaminating the spectral information. Surface action spectroscopy does not have such a problem since it is a reference-free spectroscopy. In turn, it became possible to identify the defect-related $\mathrm{V}=\mathrm{O}$ mode at $1,008 \mathrm{~cm}^{-1}$ (curve (c)), which is swamped by the background artifacts in the IRAS spectra. HREELS is also a reference-free spectroscopy (curve (d)), but HREELS spectra of ionic compounds contain intense losses related to Fuchs-Kliewer polaritons and multiple losses related to them [66], which may mask losses due to localized surface vibrations.

One may ask, what exactly are the desorption mechanism(s) in surface action spectroscopy? There are no detailed studies yet, but we have collected a number of arguments. An important parameter is the sample temperature rise as shown in curve (e), which was recorded together with the action spectrum in curve (c). Apparently, the excitation of the vanadyl vibration does not induce a sample temperature rise, whereas the excitation of the level at about $680 \mathrm{~cm}^{-1}$ does, indicating that there are two different channels for desorption of messenger atoms. In one channel, messenger desorption is induced by the excitation of levels with a strong infrared absorption cross section such as bulk polaritons, which leads to a detectable temperature rise. In the other channel surfacelocated vibrations (in the present case of vanadyl groups) trigger messenger desorption via vibrational coupling. The absorption cross section of such vibrations is rather small in general and therefore the temperature rise is below the de- 
tection limit. The first channel is bulk sensitive, possibly at least in part thermal, and can be directly correlated with the infrared reflectivity of the sample as shown by Wu et al. [28], while the other channel is surface sensitive, which makes it interesting for surface studies.

Curve (b) in Figure 10(c) shows that argon messenger atoms are not sensitive at all to vibrations of $\mathrm{V}_{2} \mathrm{O}_{3}(0001) / \mathrm{Au}$ (111). The relevant difference between argon and neon messengers is that argon has a much higher activation energy for desorption than neon $\left(660-960 \mathrm{~cm}^{-1}\right.$ vs. $\left.80-300 \mathrm{~cm}^{-1}\right)$ according to the thorough thermal desorption study of Schlichting $[67,68]$. For the bulk-sensitive channel we may simply state that the temperature rise is too small for detectable Ar desorption. Regarding the other channel we have to consider that there are many dissipation channels for the energy of an excited surface vibration-transfer of energy to the messenger-substrate bond, which might eventually lead to messenger desorption and is only one of many channels. We assume that argon atoms do not desorb because too much of the vibrational energy goes into channels which do not lead to desorption. The energy for neon desorption is significantly smaller and therefore the chance that a sufficient amount of energy is transferred is much larger. From these considerations it follows that the coupling of the excited vibration to other substrate vibrations is a relevant parameter for the desorption probability in the surface sensitive channel: the less energy is lost to excitations in the substrate, the higher the messenger desorption probability will be.

Another catalytically important oxide is ceria. $\mathrm{CeO}_{2}(111)$ films may be prepared in high structural quality on $\mathrm{Ru}$ (0001). Figure 11 shows a set of STM images at atomic resolution of a $3 \mathrm{~nm}$-thick film. The outstanding performance of ceria in promoting oxidation processes relies to a large extent on its facile reducibility and the associated

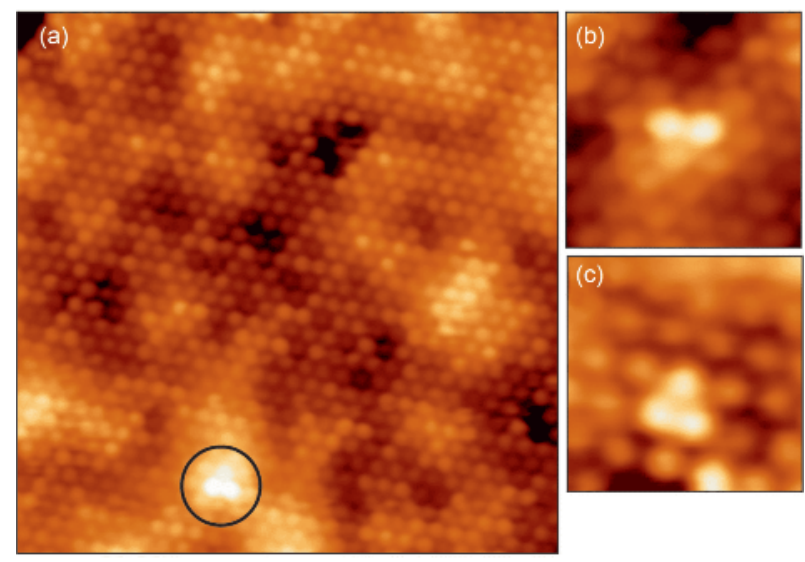

Figure 11 (a) Atomically resolved image showing the Ce sublattice $(1.2 \mathrm{~V}, 12 \mathrm{~nm} \times 12 \mathrm{~nm})$. The protrusion in the lower part is assigned to a single $\mathrm{O}$ vacancy. (b, c) Similar defects imaged with a tip configuration that is sensitive to the Ce lattice $(1.2 \mathrm{~V}, 2.4 \mathrm{~nm} \times 2.4 \mathrm{~nm})$, adapted with permission from Ref. [74], copyright by American Physical Society (2011) (color online). ability to release lattice oxygen [69]. A single oxygen vacancy is shown in the inset of Figure 10. The vacancies are easily healed again in an O-rich ambient, which makes the oxide perfectly suited to balance the oxygen supply during a catalytic reaction. On removing an $\mathrm{O}$ atom, two electrons left behind in the lattice form two reduced $\mathrm{Ce}^{3+}$ species [69]. The electrons occupy split-off states of the initially empty $\mathrm{Ce} 4 \mathrm{f}$ band, lying inside the $\mathrm{O}_{2 \mathrm{p}}-\mathrm{Ce}_{5 \mathrm{~d}}$ band gap of ceria and being highly localized in space. The reduction of ceria can be monitored with photoelectron spectroscopy, by using the presence of filled Ce $4 \mathrm{f}$ states or characteristic shifts in the Ce $3 \mathrm{~d}$ core levels as a measure [70,71]. However, this approach provides spatially averaged information, and the localization of the $\mathrm{O}$ vacancies and associated $\mathrm{Ce}^{3+}$ ion pairs cannot be revealed. STM and atomic force microscopy have been successfully employed to identify single $\mathrm{O}$ vacancies in surface or subsurface ceria layers [72,73] as shown in Figure 11. In this way, further information on the electronic properties of the defects may be obtained. In particular, the question of electron localization may be solved. Ceria films prepared in an excess of $\mathrm{O}_{2}$ exhibit only a small defect concentration. Oxygen vacancies were therefore generated by irradiating the surface with $50 \mathrm{eV}$ electrons ( $1 \mathrm{mC}$ dose) at $100 \mathrm{~K}$. At these conditions, the defects are not expected to be in an equilibrium distribution; however, most of them are located in the oxide surface given the low excitation energies. STM imaging and spectroscopy in combination with density functional theory (DFT) calculations provided a unique insight into the localization of the two excess electrons which remain in the $\mathrm{CeO}_{2}(111)$ surface upon the $\mathrm{O}$ vacancy formation.

The above discussed prototypical periodic and ordered ionic materials already have a complex structural environment, although their defect structure is still comparably simple. However, the level of complexity is even higher when it comes to the description of amorphous materials. The most prominent amorphous oxide network former for glass materials is silicon dioxide. Various branches of modern technologies are guided by the application of amorphous materials and they are used in our daily lives. They provide unique properties in semiconductor devices, optical fibers, and as supports in the field of industrial catalysis [75].

Atomic scale science characterizations for crystalline and periodic materials have been possible since the beginning of the 20th century by using X-ray diffraction. However, the interpretation of diffraction data from amorphous materials does not lead to a completely conclusive structural assignment.

Nowadays the general attempt by Zachariasen [76] for providing an atomic model for glass structures is referenced as the so-called "Random Network Theory". He reduced the three dimensional connectivity of tetrahedral silica units into a two dimensional plane and provided thereby the textbook 

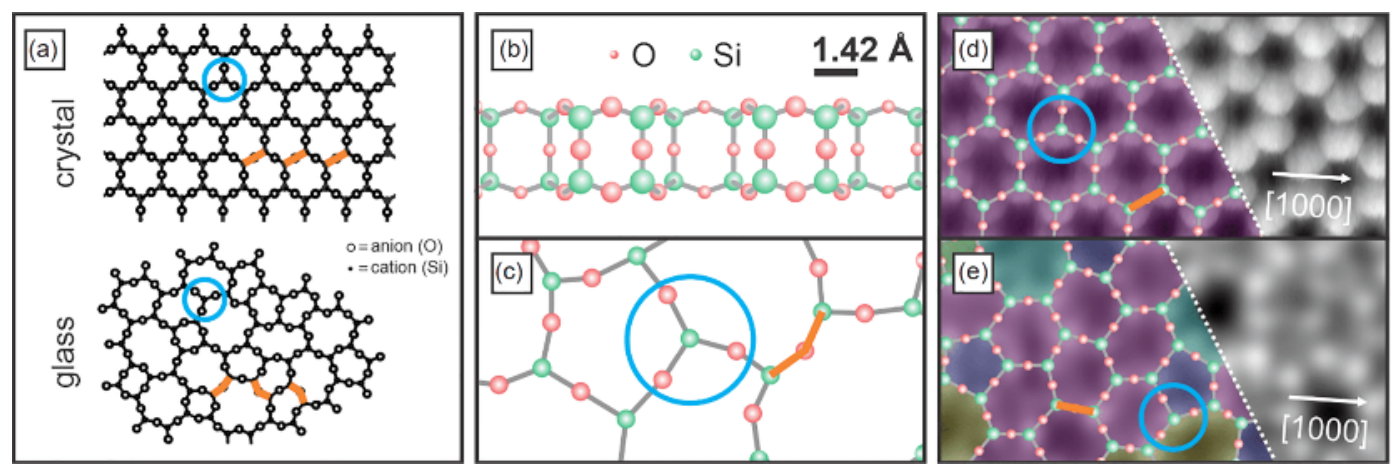

Figure 12 (a) Original scheme of the crystalline and glass network structures by Zachariasen, adapted with permission from Ref. [76], Copyright by American Chemical Society (1932). Side and top view of the silica bilayer film are provided in (b) and (c) together with atomically resolved crystalline (d) and vitreous (e) regions of the thin silica film as seen by STM. The scan area of image (d) and (e) is $1.7 \mathrm{~nm} \times 3.5 \mathrm{~nm}$, adapted with permission from Ref. [77], copyright by American Chemical Society (2012). The STM images are superimposed with an atomic model of the topmost layer of the silica film (green balls: Si atoms, red balls: O atoms) (color online).

example for crystal and glass structures. The original schemes are reproduced in Figure 12(a). In his model the $\mathrm{Si}-$ $\mathrm{O}-\mathrm{Si}$ angle is fixed to $180^{\circ}$ for the crystalline structure. In case of the glass structure this angle has a certain variation and allows for the development of different ring sizes. Nevertheless, the stoichiometry and connectivity are in both cases still maintained. These schemes nicely resemble the generally accepted concept for glass structures. The building blocks have been rendered with blue circles in Figure 12.

Also, here the surface science approach has provided insights into atomic scale features of glass materials. The combination of thin film growth methods with high resolution scanning probe microscopy techniques has revealed clear images that resolved in real space the silica network structure. Depending on the film preparation conditions STM images of its crystalline or amorphous phase can be obtained [77]. The development of a silica bilayer film was in this case a key ingredient. A side and top view of the atomic model from the silica bilayer together with high resolution STM images are provided in Figure 12.

Besides its great success in resolving amorphous materials for the first time, the silica film system has started to become a research topic of its own. It provides unique properties and is a great addition to the class of two-dimensional (2D) materials. A recent review paper summarizes and references the current trends and developments in this respect [78].

\subsection{Doping of oxide films}

Nonreducible oxides are characterized by large band gaps and are therefore unable to exchange electrons or to form bonds with surface species, explaining their chemical inertness. The insertion of aliovalent dopants alters this situation, as new electronic states become available in the gap that may be involved in charge-transfer processes [79]. Consequently, the adsorption and reactivity pattern of doped oxides changes with respect to their non-doped counterparts. By this means, all advantages of charge control (see below) could be maintained for oxide slabs of arbitrary thickness. Although the fundamental concepts of doping were introduced and brought to perfection in the semiconductor technology already decades ago, a direct transfer to oxide materials is challenging due to several structural and electronic peculiarities [80]. Oxides are subject to self-doping by native defects and unwanted impurities, the concentration of which is difficult to control experimentally [81]. Both lattice defects and impurity ions may adopt different charge states in the oxide matrix, a variability that leads to pronounced compensation effects and is less common in semiconductors. And finally, the dopants may be electrically inactive in widegap oxides, as thermal excitation is insufficient to promote electrons from the defect states to the bulk bands. The excess charges thus remain trapped at the host ions and are unavailable for charge transfer. Nonetheless, doping is a versatile approach to tailor the properties of bulk-like oxides as well. In general, doping is carried out with impurity ions that adopt either a higher or a lower valence state than the native oxide ions (Figure 13(a, b)) [79]. Whereas high-valence dopants may serve as charge donors and provide extra electrons, lowvalent dopants have acceptor character and may accommodate electrons from suitable adsorbates. In rare cases, charge-preserving doping is realized where geometric and strain effects are exploited to modify the oxide properties.

Two approaches were employed to prepare oxide films with a controlled doping level. In the first one, the host material was evaporated simultaneously with the dopants in an $\mathrm{O}_{2}$ ambience of $10^{-5}$ to $10^{-7} \mathrm{mbar}$. The scheme was used for example to load $\mathrm{MgO}$ thin films with either $\mathrm{Cr}$, $\mathrm{Eu}$, or $\mathrm{Li}$ impurities $[82,83]$. The main drawback of the technique was the uncontrolled diffusion of the dopants during film annealing, followed by the formation of dopant-rich surface phases. By contrast, the segregation of substrate atoms into the oxide film was exploited in the second approach, used for instance to prepare Mo-doped $\mathrm{CaO}$. Upon $\mathrm{CaO}$ deposition on 


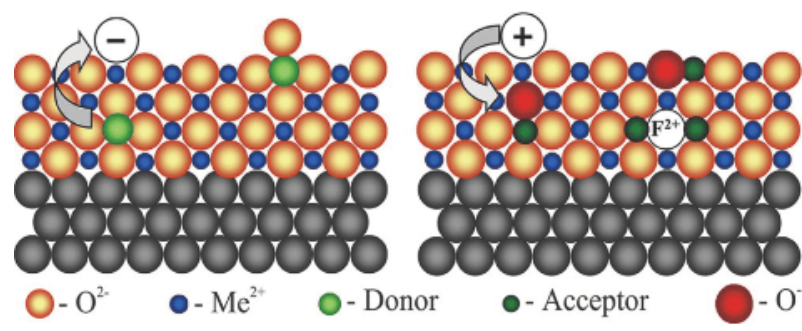

Figure 13 Schematic representation of an oxide film on top of a metal (black) substrate. High-valence dopants to have donor character as they transfer electrons to the surface, while low-valence dopants on the other hand give rise to an acceptor response, adapted with permission from Ref. [85], copyright by American Chemical Society (2015) (color online).

the $\mathrm{Mo}(001)$ support, a considerable misfit strain is generated at the interface due to the $8 \%$ larger lattice parameter of the oxide. The strain gets partly released by incorporating up to $25 \%$ Mo ions into the growing film, because the $\mathrm{Mo}-\mathrm{O}$ bond length is considerably shorter than the $\mathrm{Ca}-\mathrm{O}$ distance [84]. The mixed oxide at the interface now forms an ideal starting point for Mo diffusion into the $\mathrm{CaO}$ matrix, whereby the desired Mo concentration in a near-surface region can be adjusted by changing either the film thickness or the growth temperature.

Although the strain-driven diffusion avoids the dopant accumulation at the surface, it generates a falling doping profile when moving away from the metal support. Other doping techniques involve high-energy sputtering of impurities as well as various wet-chemical approaches. The presence of the dopants may, of course, be verified via X-ray photoelectron spectroscopy, and their electronic structure may be analyzed via chemical shifts, but, on a local basis also scanning tunneling spectroscopy has been used. The distinct electronic structure of transition metal ions in rocksalt oxides gives rise to a tip-induced charging mechanism that renders individual dopants visible in the STM, although no atomic resolution is obtained on the insulator and most dopants reside below the surface [86]. Especially on well-ordered $\mathrm{CaO}_{\mathrm{Mo}}$ films, concentric rings with diameters depending on imaging bias and film thickness can be detected (Figure 14 (a)). The rings reflect a temporary charging of the Mo impurities in the oxide lattice, triggered by the electric field of the STM tip (Figure 14(b)) [87]. At the negative tip bias used for imaging, the oxide bands experience a localized upward bending around the tip position. The dopant-induced energy levels follow this trend, whereby the highest occupied orbital may shift above the conduction band onset in a more distant, hence less affected, $\mathrm{CaO}$ region. At this condition, Mo transfers an electron to the $\mathrm{CaO}$ matrix and becomes more oxidized. The resulting positive net-charge polarizes the surrounding lattice and changes its imaging contrast in the STM, producing the concentric rings seen in Figure 14(a). Using calculated energy gaps between the highest occupied
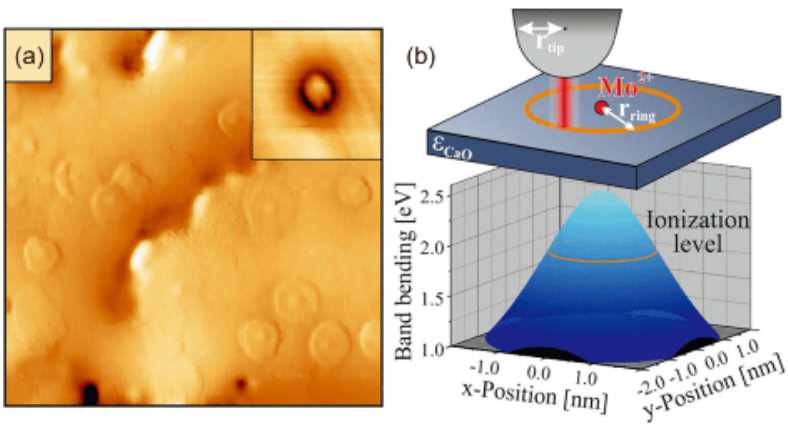

Figure 14 (a) STM image of $25 \mathrm{ML} \mathrm{CaO}$, showing characteristic Moinduced charging rings $(30 \mathrm{~nm} \times 30 \mathrm{~nm}$ ). (b) Real-space model of a charging ring and underlying shift of the $\mathrm{Mo}^{2+}$ highest occupied molecular orbital (HOMO) calculated for $5.0 \mathrm{~V}$ sample bias and $2.5 \mathrm{~nm}$ tip radius. Electron transfer into the $\mathrm{CaO}$ conduction band takes place if the level crosses the orange line. An individual defect is depicted in the inset $(5 \mathrm{~nm} \times 5 \mathrm{~nm})$, adapted with permission from Ref. [85], copyright by American Chemical Society (2015) (color online).

Mo $4 \mathrm{~d}$ states and the conduction band onset, the ring diameter has been correlated with the charge state and position of the Mo donor below the surface [86]. The analysis revealed that only $\mathrm{Mo}^{2+}$ ions in the first three subsurface layers are susceptible to a tip-induced ionization and give rise to the charging rings seen on the surface. For higher Mo oxidation states or positions deeper inside the film, either the energy gap is too large or the tip electric field is too weak to stimulate charge-transfer processes out of the impurities. Because tip-induced switches of the oxidation state require similar electronic preconditions as a permanent charge transfer into an adsorbate, the ring-producing entities will be particularly relevant for the donor character of the doped oxide.

\subsection{Charge-transfer on and in thin oxide films}

$\mathrm{MgO}$ as the prototype of an ionic oxide is a good starting point for the discussion of charge transfer effects on thin oxide films. The interaction of molecules as well as metal atoms with the stoichiometric (001)-plane of the rock salt lattice is rather weak resulting in a low stability of individual metal atoms and growth of 3-dimensional metal particles at ambient temperature. Gold atoms adsorbed on bulk like 30 $\mathrm{ML} \mathrm{MgO(001)} \mathrm{films} \mathrm{were} \mathrm{shown} \mathrm{to} \mathrm{be} \mathrm{neutral} \mathrm{entities} \mathrm{[88].}$ However, the binding of the atoms on top of oxygen ions in the $\mathrm{MgO}$ lattice leads to a polarization of the valence electrons of the $\mathrm{Au}$ atom, which enables charge transfer to molecular adsorbates such as CO [89]. It had been proposed theoretically that $\mathrm{Au}$ atoms deposited onto ultrathin $\mathrm{MgO}$ films get negatively charged due to an electron charge transfer from the metal substrate to the $\mathrm{Au}$ atom [90-92]. This is due to the fact that the unoccupied part of the Au $6 \mathrm{~s}$ level that locates inside the band gap on thick films shifts below the Fermi-energy in a metal-supported thin film sys- 
tem. There are different contributions to this effect. First, the deposition of $\mathrm{MgO}$ onto the metal substrate reduces the work function of the system, which has been confirmed both theoretically as well as experimentally $[33,93,94]$. Secondly, charged $\mathrm{Au}$ atoms adsorbed on the surface of the ultrathin $\mathrm{MgO}$ film are stabilized by polaronic distortions of the oxide lattice $[91,95]$.

Experimental evidence for the charging of $\mathrm{Au}$ atoms on ultrathin $\mathrm{MgO}(001)$ films comes from low-temperature STM experiments. As seen from the STM image in Figure 15(a), $\mathrm{Au}$ atoms deposited on a $3 \mathrm{ML} \mathrm{MgO}$ film $(T=5-10 \mathrm{~K})$ form a structure indicating significant repulsion between them [96]. By contrast, the adsorption of Pd atoms on $3 \mathrm{ML} \mathrm{MgO} \mathrm{films}$ (not shown) is in perfect agreement with expectations based on a statistical distribution of the atoms [96]. Further evidence for a charged state of the Au atoms can be found from the STM signatures of single Au atoms in comparison with simulated ones applying the Tersoff-Hamann approximation (Figure 15(b, c)) [97]. The experimental appearance of the Au atoms, showing a "sombrero-like" protrusion surrounded by a depression, is nicely reproduced theoretically. However, it is absent in calculated STM images of the neutral atoms [98]. Similar observations were found for other systems such as $\mathrm{Au}$ on ultrathin $\mathrm{NaCl}$ films [99]. To elucidate this question in more detail it is interesting to note that on bulk $\mathrm{MgO}$ or thick films $\mathrm{Au}$ atoms were found to nucleate exclusively on top of oxygen ions [88], while the theory predicts charged $\mathrm{Au}$ atoms on thin films to adsorb preferably on $\mathrm{Mg}$ ions or hollow sites $[90,91,100]$. STM can provide evidence for this change in the distribution of adsorption sites by superimposing the $\mathrm{MgO}$ lattice onto the STM images of Au atoms. For an $8 \mathrm{ML}$ film more than $80 \%$ of the atoms occupy one adsorption site, while at least two different adsorption sites are populated with almost equal probability on $3 \mathrm{ML}$ films (Figure 15(d)), which clearly shows the change in adsorption sites [96].

Charge transfer is not restricted to metal atoms with the sufficiently high electron affinity, but was theoretically predicted for molecules with high electron affinities such as $\mathrm{NO}_{2}$ or $\mathrm{O}_{2}$ adsorbed on ultrathin $\mathrm{MgO}(001)$ films grown on $\operatorname{Ag}(001)$ or $\mathrm{Mo}(001)[95,101,102]$. From an experimental point of view the characterization of the superoxide anion $\left(\mathrm{O}_{2}{ }^{-}\right)$can be approached using EPR spectroscopy [23] as the superoxide anion is a radical with a doublet ground state. Figure 16(a) shows an EPR spectrum of molecular oxygen adsorbed at $40 \mathrm{~K}$ on a $4 \mathrm{ML}$ thick $\mathrm{MgO}(001)$ film grown on $\mathrm{Mo}(001)$ [42]. The spectrum consists of a doublet of lines at $g$-values of 2.072 and 2.002, which are well in line with expectations based on $\mathrm{O}_{2}{ }^{-}$radicals observed on $\mathrm{MgO}$ powder [103-105]. In line with theoretical predictions, the radicals show significant stability $\left(T_{\mathrm{des}} \approx 350 \mathrm{~K}\right)$ and disappear for thicker $\mathrm{MgO}$ films (>15 ML). A detailed analysis of angle
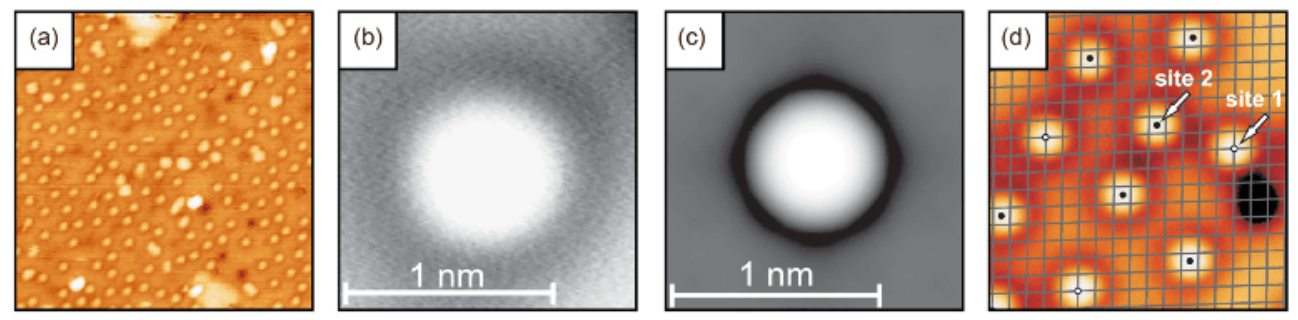

Figure 15 (a) STM image ( $30 \mathrm{~nm} \times 30 \mathrm{~nm}$ ) of Au atoms adsorbed on a $3 \mathrm{ML}$ thin $\mathrm{MgO}$ film. (b) Experimental STM image and (c) calculated STM image of

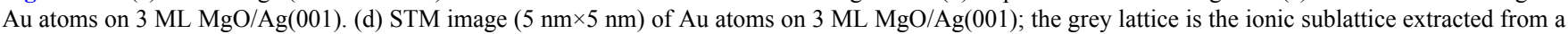
high resolution image of the clean MgO film, adapted with permission from Refs. [96], copyright by American Physical Society (2007), adapted with permission from Ref. [97], copyright by American Physical Society (1985) (color online).
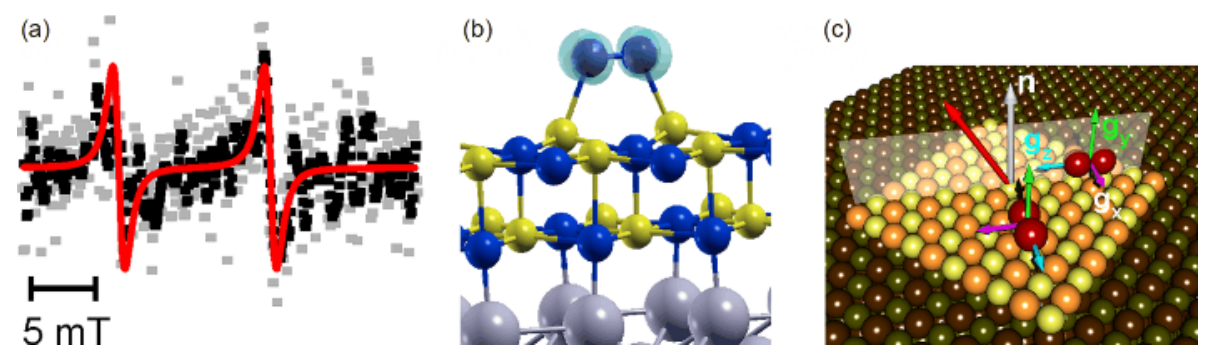

Figure 16 (a) EPR spectrum of $20 \mathrm{~L} \mathrm{O}_{2}$ adsorbed at $40 \mathrm{~K}$ on a $4 \mathrm{ML}$ thick $\mathrm{MgO}(001)$ film on $\mathrm{Mo}(001)$ with the magnetic field in the surface plane along a [110] equivalent direction. (b) Result of a DFT calculation of $\mathrm{O}_{2}$ on a $2 \mathrm{ML}$ thin $\mathrm{MgO}(001)$ film on $\mathrm{Mo}(001)$ showing the polaronic distortion of the MgO lattice. (c) Sketch of oxygen molecules adsorbed on $2 \mathrm{ML} \mathrm{MgO}$ films as predicted by theory. The transparent area indicates the plane in which the magnetic field was lying in (a). The orientations of the three principal components of the $g$-matrix of the two symmetry equivalent molecules are shown as color coded arrows. As an EPR experiment probes the $g$-value oriented along the static magnetic field it is readily clear that both molecules are not identical to the magnetic field lying in the surface plane. Adapted with permission from Ref. [42], copyright by John Wiley and Sons (2011) (color online). 
dependent spectra reveals that the $\mathrm{O}_{2}^{-}$radicals are adsorbed on the terraces of the $\mathrm{MgO}(001)$ surface aligned with equivalent directions as predicted theoretically (Figure 16 (b)). A comparison of the $\boldsymbol{g}_{\mathrm{zz}}$ component (for an alignment of the $g$-matrix with the molecular framework see Figure 16(c)) of the $g$-matrix $\left(g_{\mathrm{zz}}=2.072\right)$ with values observed for $\mathrm{O}_{2}{ }^{-}$ radicals on terraces of $\mathrm{MgO}$ powders $\left(\mathrm{g}_{\mathrm{zz}}=2.091\right)$ [104] provides additional physical insight into the interaction between the molecule and the surface as the observed value depends critically on local electric fields experienced by the radical. The reduction of the $\boldsymbol{g}_{\text {zz }}$ component on the film as compared to bulk $\mathrm{MgO}$ is associated with an increase of the local electric field, which is due to the polaronic distortion of the $\mathrm{MgO}$ lattice in case of the ultrathin film (Figure 16(b)) as revealed by quantum chemical calculations [42].

A case where such charge transfer is not an obvious option is illustrated by the interaction of hydrogen with reduced ceria [106]. We have discussed above the preparation and identification of oxygen vacancies in reduced ceria. The interaction of ceria with hydrogen has recently gained increasing interest, since it was reported that ceria may be used as a catalyst for selective hydrogenation of alkynes (triplebonded unsaturated hydrocarbons) to alkenes (double-bonded hydrocarbons) [107-112]. We have studied the interaction of $\mathrm{H}_{2}$ with $\mathrm{CeO}_{2}(111)$ crystalline films using XPS and electron energy loss spectroscopy [106]. Figure 17 shows Ce $3 \mathrm{~d}$ spectra obtained at grazing emission before and after exposure of a reduced ceria film to $10 \mathrm{mbar}$ of $\mathrm{H}_{2}$ at $300 \mathrm{~K}$. From the fit of the spectra we found that the amount of $\mathrm{Ce}^{3+}$ at the surface considerably decreased upon reactions with $\mathrm{H}_{2}$ thus indicating that hydrogen oxidizes $\mathrm{CeO}_{2}(111)$, which sounds like a contradiction. How can hydrogen oxidize reduced ceria? The answer is relatively simple. The hydrogen molecules dissociate as they penetrate the ceria and the $\mathrm{Ce}^{3+}$ ions transfer their $4 \mathrm{f}$ electrons to the hydrogen atoms forming a hydride. This results in ceria ions in the $4+$ state, i.e., ceria is oxidized.
Figure 18 shows electron energy loss spectra in the valence electron excitation regime, before reduction (bottom), after reduction (center) and after exposure to hydrogen (top). While the fully oxidized $\mathrm{CeO}_{2}(111)$ shows the well-known spectrum of valence excitations (Figure 18, black curve a), it is strongly altered upon reduction (purple curve), and fully restored upon hydrogen exposure (orange curve), a third and final example indicating the oxidation of ceria through the formation of hydrides.

We have already shown that single Au atoms become charged upon adsorption on very thin $\mathrm{MgO}(001)$ films. Similar observations have been made for Au aggregates on a number of thin-film substrates [106]. We demonstrate this on $\mathrm{Au}$ aggregates adsorbed on alumina. Here we may use the ability of the STM to record the electronic spectra of a system at the local scale via $\mathrm{d} I / \mathrm{d} V$ measurements to count, as we will show below, the number of electrons on the deposited $\mathrm{Au}$ aggregate. The first report to experimentally count the number of electrons in a linear metal aggregate was given by Nilius et al. [113] together with computational studies by the Sauer's group in 2008. As shown in Figure 19, the important feature here is the observation of patterns in the $\mathrm{d} I / \mathrm{d} V$ spectroscopic images that represent the quantum states of the system as a function of the tunneling voltage [114]. Identifying the highest occupied and lowest unoccupied states of the chain, and knowing the number of atoms in the chain permit to count the number of transfer-electrons provided by the substrate.

The idea is to use the concept of a particle-in-a-box and the number of nodes in the wave functions as a function of energy. The result in case of a chain of seven Au atoms on an alumina film is that three electrons have been transferred to the $\mathrm{Au}$ chain in addition to the intrinsic electrons of the $\mathrm{Au}$ atoms in the chain. The next step is to proceed to the investigation of nano-particles of arbitrary symmetry. Theory predicted that charge transfer onto the gold particles leads to the formation of 2-dimensional structures on ultrathin $\mathrm{MgO}$

\section{$\mathrm{CeO}_{2 \cdot x}(111)$ Thin Films}

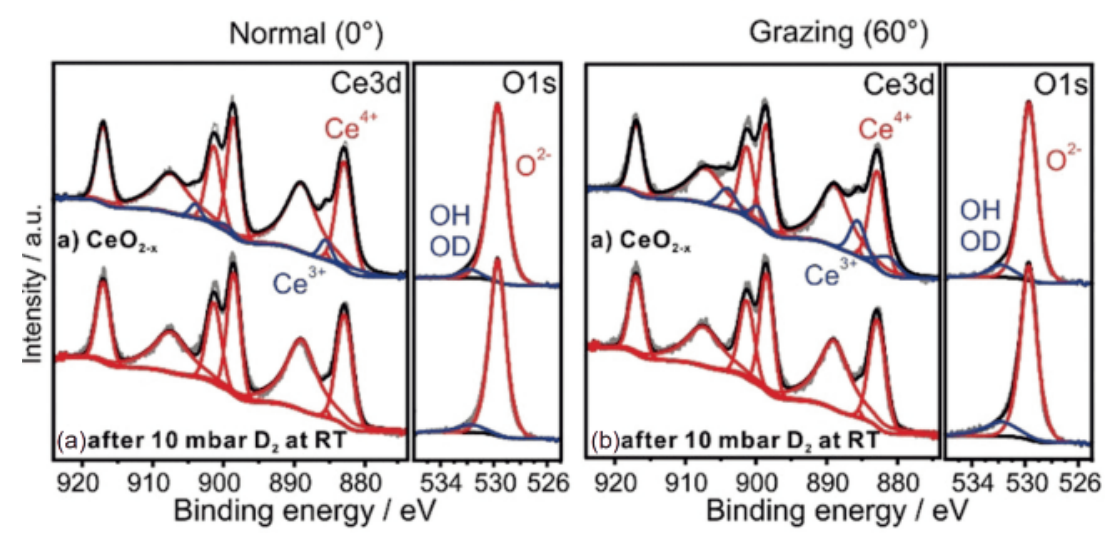

Figure $17 \mathrm{Ce} 3 \mathrm{~d}$ and $\mathrm{O} 1 \mathrm{~s}$ XPS spectra of $\mathrm{CeO}_{2-x}(111)$ thin film in normal $\left(0^{\circ}\right)$ and grazing $\left(60^{\circ}\right)$ emission geometry. (a) Freshly prepared CeO ${ }_{2-x}(111)$; (b) $\mathrm{CeO}_{2-x}(111)$ exposed to 10 mbar $\mathrm{D}_{2}$ at $300 \mathrm{~K}$, adapted with permission from Ref. [106], copyright by John Wiley and Sons (2019) (color online). 


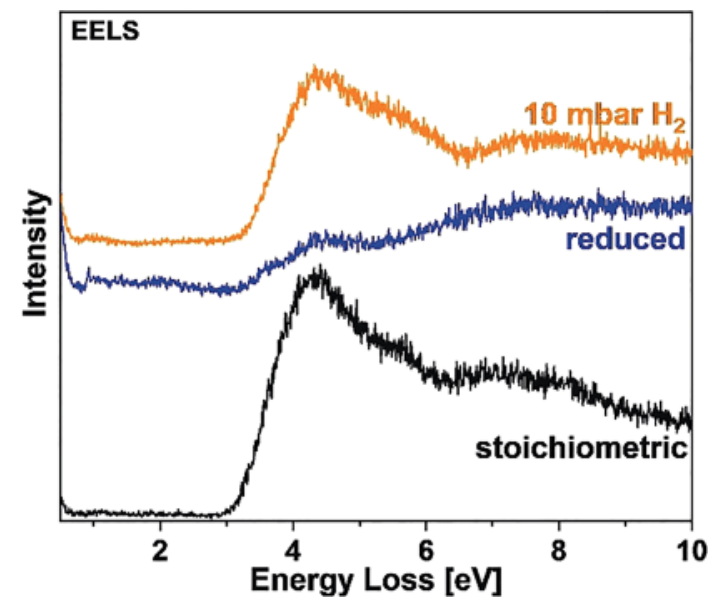

Figure 18 EELS spectra of differently prepared $\mathrm{CeO}_{2}(111)$ thin film surfaces. Reduction of $\mathrm{CeO}_{2}(111)$ to $\mathrm{CeO}_{2-x}(111)$ was achieved by annealing in UHV. The reduced $\mathrm{CeO}_{2-x}(111)$ film was then exposed to 10 mbar $\mathrm{H}_{2}$ at $300 \mathrm{~K}$ for $15 \mathrm{~min}$. The spectra were recorded in sequence from the bottom to the top, adapted with permission from Ref. [106], copyright by John Wiley and Sons (2019) (color online).

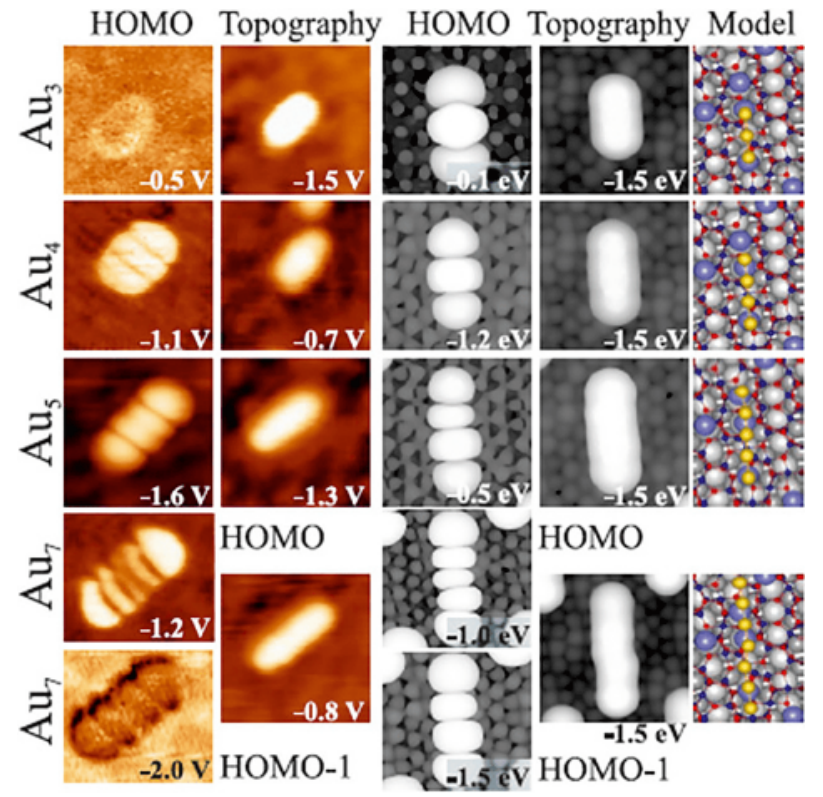

Figure 19 Experimental and calculated HOMO shapes, topographies, and model structures for $\mathrm{Au}_{3}, \mathrm{Au}_{4}, \mathrm{Au}_{5}$, and $\mathrm{Au}_{7}$ chains. Images are 5.0 $\mathrm{nm} \times 5.0 \mathrm{~nm}$ in size. For the $\mathrm{Au}_{7}$ chain, in addition, the HOMO-1 is shown. Measured chain lengths are $0.9,1.2,1.5$, and $2.2 \mathrm{~nm}$; calculated distances between first and last chain atoms amount to $0.53,0.78,1.05$, and $1.55 \mathrm{~nm}$. To compare theoretical to experimental lengths, $0.2-0.3 \mathrm{~nm}$ should be added to both chain sides to account for the diffusivity of the 1D orbitals, adapted with permission from Ref. [113], copyright by the American Physical Society (2008) (color online).

films in contrast to bulk $\mathrm{MgO}$, where 3-dimensional particles are expected [115-117]. The reduced stability of the 2-dimensional structures on thick films is due to the vanishing charge transfer into the Au aggregates as well as the increasing cost for the polaronic distortion with increasing the film thickness. The latter is caused by a stiffening of the
$\mathrm{MgO}$ lattice due to the long-range nature of the Coulomb interaction. A low-temperature STM study provided experimental evidences for the predicted crossover in the growth mode. For an $8 \mathrm{ML} \mathrm{MgO} / \mathrm{Ag}(001)$-film 3-dimensional particles are observed after annealing to room temperature, whereas the Au-particles on $3 \mathrm{ML} \mathrm{MgO} / \mathrm{Ag}(001)$ stay 2-dimensional after the corresponding careful annealing step [96]. A heating to higher temperatures in the range of $450 \mathrm{~K}$ leads to a reconfiguration into $3 \mathrm{D}$ islands.

An analysis aiming at the determination of charges accumulated by the $2 \mathrm{D}$ islands of $\mathrm{Au}$ on $\mathrm{MgO}(100)$ has been presented by Lin et al. [118]. Here the analysis, based on computations performed by the Hakkinen's group, revealed the patterns that were analyzed in a similar way as for the linear chain discussed before, yet taking into account the two-dimensional nature of the problem. The experimental and computational results for an $\mathrm{Au}_{18}$ nanoparticle are illustrated in Figure 20. In this case, four extra electrons are transferred to the flat two-dimensional Au nanoparticle according to the analysis.

Lin et al. [119] performed studies on larger objects containing 100 atoms. Here the geometry, in particular at the rim of the flat raft as shown in Figure 21(a), is complex, which
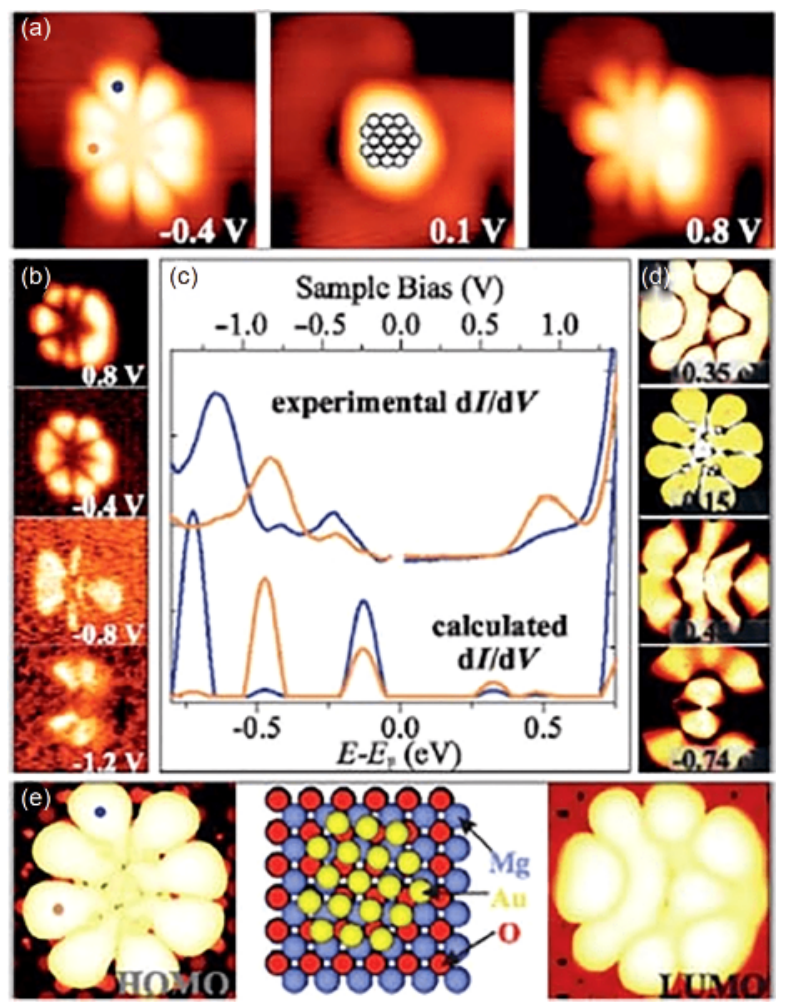

Figure 20 (a) STM topographic and (b) conductance images of an $\mathrm{Au}_{18}$ cluster on $2 \mathrm{ML} \mathrm{MgO} / \mathrm{Ag}(001)\left(I_{\mathrm{t}}=5 \mathrm{pA}, 3.9 \mathrm{~nm} \times 3.9 \mathrm{~nm}\right)$ in comparison with simulated (d) conductance and (e) topographic images $(2.0 \mathrm{~nm} \times$ $2.0 \mathrm{~nm}$ ) and a structures model. (c) Experimental and simulated $\mathrm{d} I / \mathrm{d} V$ spectra taken at the blue and orange dots marked on the cluster in (a) and (e), adapted with permission from Ref. [119], Copyright by the American Physical Society (2009) (color online). 

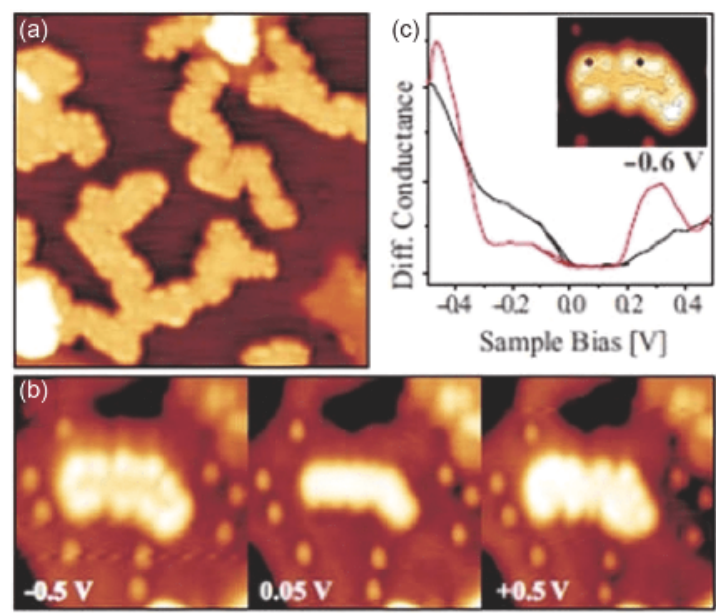

Figure 21 (a) STM topographic images of planar Au islands on $2 \mathrm{ML}$ $\mathrm{MgO} / \mathrm{Ag}(001)\left(V_{\mathrm{s}}=0.2 \mathrm{~V}, 25 \mathrm{~nm} \times 25 \mathrm{~nm}\right)$. (b) Au island and single adatoms imaged at different bias voltages (scan size $10 \mathrm{~nm} \times 10 \mathrm{~nm}$ ). (c) Conductance spectra taken on a kink and a step position of the island shown in the inset. The bias set point was $+0.5 \mathrm{~V}$. The locally increased density of states at the cluster rim is clearly observed in (b) and (c) indicating the presence of a negatively charged $2 \mathrm{D}$-Au cluster, adapted with permission from Ref. [119], copyright by the American Physical Society (2010) (color online).

renders an analysis with respect to symmetry properties difficult. Still, according to the theoretical results there is charge transfer to the Au raft of about 0.2e per Au atom. The complexity in the structure expresses itself by partial localization of the additional charges at specific sites on the rim. Figure 21(b), presenting filled and empty states of the $\mathrm{Au}$ nanoparticle, illustrates this finding. Hakkinen's calculations predict that the localization happens preferentially at kink sites on the rim. There is almost a full extra electron at a kink site, as compared to $0.5 e$ at the other perimeter $\mathrm{Au}$ atoms.

This appears to be an interesting result because the charge localization may influence the adsorption of molecules. There are several sets of experiments in the literature concerning edge states on non-metallic particles. An early one came from the Besenbacher's group [120] on $\mathrm{MoS}_{2}$ in which the authors observe edge states when those sulfide rafts are supported on an $\mathrm{Au}(111)$ surface.

In these two-dimensional nanoparticle systems, there is obviously no problem to observe details on the perimeter. The question is whether such observations may be transferred to three-dimensional supported particles. This is a challenge, and so far, no clear evidence has been reported.

Based on the above considerations, we expect that charge donors inserted in a bulk-like oxide lattice may resume the role of the metal support in the case of ultrathin oxide films. This assumption has first been verified in studies of the growth morphology of gold on crystalline $\mathrm{CaO}(100)$ doped with trace amounts of Mo (Figure 22) [121]. On the doped oxide, gold was found to spread out into extended monolayer islands, while the conventional 3D growth prevailed on the non-doped material. Evidently, the donor character of the Mo
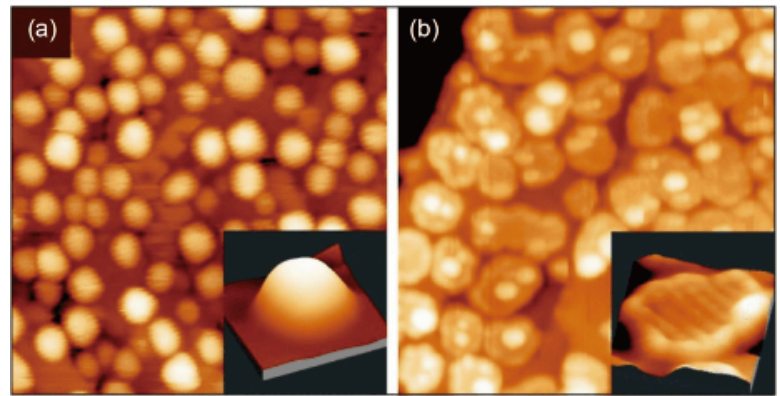

Figure 22 STM images of 0.7 ML Au deposited onto (a) pristine and (b) doped $\mathrm{CaO}$ films $(4.5 \mathrm{~V}, 50 \mathrm{~nm} \times 50 \mathrm{~nm})$. The insets display close-up images of two characteristic particles $(-5.0 \mathrm{~V}, 10 \mathrm{~nm} \times 10 \mathrm{~nm})$, adapted with permission from Ref. [121], copyright by John Wiley and Sons (2011) (color online).

ions is responsible for the 2D growth morphology, while the metal-oxide adhesion on pristine $\mathrm{CaO}(100)$ is negligible.

According to DFT calculations, Mo dopants in $\mathrm{CaO}$ mainly occupy $\mathrm{Ca}$ substitutional sites and adopt the typical $2+$ charge state of the rock salt lattice. In the 2+ oxidation state, four Mo $4 \mathrm{~d}$ electrons are localized in the dopant, three of them occupying $\left(\mathrm{t}_{2 \mathrm{~g}}-\alpha\right)$ crystal field states and one sitting in a $\left(t_{2 g}-\beta\right)$ level close to the conduction band onset (Figure 21(c)) [122]. Especially, the latter is in an energetically unfavorable position and thus susceptible to be transferred into an acceptor state with lower energy. Such states are provided by the Au ad-atoms that exhibit a half-filled Au 6s affinity level, being ready to take the topmost Mo $4 \mathrm{~d}$ electron. The result is an $\mathrm{Au}^{-}$anion that, as discussed before, experiences reinforced bonding to the $\mathrm{CaO}$ surface. DFT calculations find an increase of the binding energy from $\sim 1.5$ to $\sim 3.5 \mathrm{eV}$ upon doping, whereby the electrically-active Mo ion may be located up to ten layers below the $\mathrm{CaO}$ surface [121]. Moreover, not only $\mathrm{Mo}^{2+}$ ions are susceptible to electron transfer into gold, but also $\mathrm{Mo}^{3+}$ and $\mathrm{Mo}^{4+}$ are active donors as their topmost occupied d states are still higher in energy than the $\mathrm{Au}$ 6s affinity level [122]. Mo impurities in the $\mathrm{CaO}$ lattice are therefore robust electron donors, and as such directly responsible for the $2 \mathrm{D}$ growth of gold found experimentally [121].

The presence of suitable dopants is, however, not the only requirement for a stable donor characteristic and also the interplay between dopants and the host oxide governs the redox activity, as shown for $\mathrm{Cr}$-doped $\mathrm{MgO}$ films [82]. Although chromium has a similar electronic structure as Mo, i.e., the same number of $d$ electrons, it is unable to influence the $\mathrm{Au}$ growth on $\mathrm{MgO}$ supports. Even at high $\mathrm{Cr}$ concentration, gold adopts 3D shapes and hardly any 2D islands are found on the surface [123]. The reason is the low energy position of the $\mathrm{Cr}_{2 \mathrm{~g}}$ levels in the $\mathrm{MgO}$ band-gap, reflecting the large stabilization effect of the $\mathrm{MgO}$ crystal field on the $\mathrm{Cr}$ electrons. Note that the crystal field in $\mathrm{MgO}$ is much stronger than that in $\mathrm{CaO}$ given the larger lattice parameter of the latter [124]. In addition, the $\mathrm{Cr}$ ionization energies are 
higher than those for Mo, and the formation of $\mathrm{Cr}^{4+}$ and $\mathrm{Cr}^{5+}$ ions is energetically costive. As a result, $\mathrm{Cr}$ is able to donate only a single electron to gold, which compares to three in the case of $\mathrm{Mo}$ ions in $\mathrm{CaO}$ [82,122]. More critically, not even this electron may reach the Au particles-metal, but is likely captured by parasitic electron traps in the oxides, such as cationic defects or grain boundaries. Accordingly, an effective compensation mechanism becomes available that fully annihilates the donor character of the $\mathrm{Cr}$ ions. Because Mo impurities in $\mathrm{CaO}$ are able to release more electrons, full charge compensation is impossible and the impact of the donors prevails in that case.

\section{Chemistry and model catalysts}

\subsection{Chemistry at metal particles on oxides}

Our initial attempts to grow well structured nano-particles on thin oxide film supports dealt with Pd on alumina [125]. Figure 23 shows atomically resolved STM images of such Pd nanoparticles on the above described alumina film. One may image the substrate as well as the top terrace of the nanoparticles. However, the rim at the direct contact between the
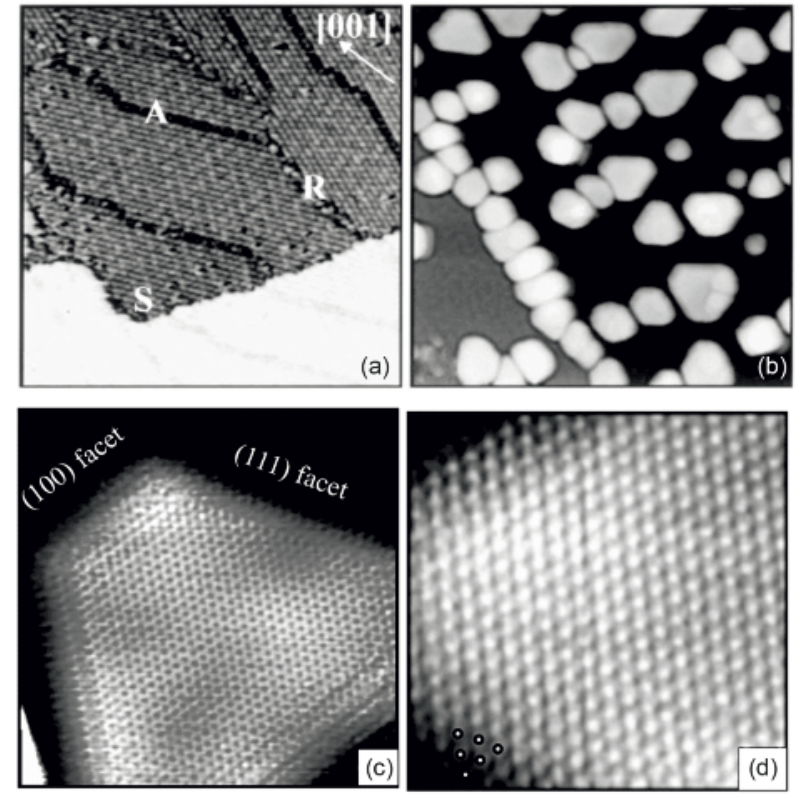

Figure 23 (a) A STM image $(500 \AA \times 500 \AA)$ of the aluminum oxide film formed on $\mathrm{NiAl}(110)$ by oxidation. A step edge (S), a reflection domain boundary (R), as well as an antiphase domain boundary (A) are indicated. Tunnel current $I_{\mathrm{t}}=-0.4 \mathrm{nA}$, sample bias $V_{\mathrm{s}}=-1.3 \mathrm{~V}$. (b) A $650 \AA \times 650 \AA$ image recorded after deposition of $\sim 2 \mathrm{ML}$ of $\mathrm{Pd}$ at room temperature. Palladium clusters have nucleated preferentially at a step and at domain boundaries. Both crystalline and less ordered clusters are seen. $I_{\mathrm{t}}=-1.0 \mathrm{nA}$, $V_{\mathrm{s}}=-0.9 \mathrm{~V}$. Atomic-resolution images of crystalline nanosize Pd clusters. (c) $95 \AA \times 95 \AA, I_{\mathrm{t}}=-0.8 \mathrm{nA}, V_{\mathrm{s}}=-5.0 \mathrm{mV}$. (d) $45 \AA \times 45 \AA$. The resolution is kept a few layers down the sides, allowing identification of the side facets. The dots indicate that atomic positions are consistent with a (111) facet. $I_{\mathrm{t}}=0-1.8 \mathrm{nA}, V_{\mathrm{s}}=-1.5 \mathrm{mV}$, adapted with permission from Ref. [125], copyright by John Wiley and Sons (1999). metals cannot be imaged. This is to be contrasted to the raft $\mathrm{Au}$ particles created via charge transfer on the thin $\mathrm{MgO}$ (100) films, where we were able to image the metal oxide interface directly. We will come back to this in an example below.

We will first discuss a classical reaction connected with hydrogenation of unsaturated hydrocarbons on supported $\mathrm{Pd}$ nano-particles using a magnetite $\left(\mathrm{Fe}_{3} \mathrm{O}_{4}(111)\right)$ support grown on $\mathrm{Pt}(111)$ and the importance of carbon deposits on the metal particles. Hydrogenation rates of cis-2-butene over clean and C-containing Pd nanoparticles supported on $\mathrm{Fe}_{3} \mathrm{O}_{4}$ (111)/Pt(111) film are shown in Figure 24(a). Pd nanoparticles were saturated first with deuterium to form both surface and subsurface D species [126] and then short pulses of cis-2-butene were applied. Clean Pd nanoparticles exhibit high hydrogenation activity for an initial short period of time (a few butene pulses), after which it drops to zero. By contrast, if carbon was deposited on Pd nanoparticles before the reaction, a sustained hydrogenation rate was observed (Figure 24(b)). Using CO as a probe molecule for different adsorption sites, it can be shown that deposited carbon modifies the low-coordinated site such as edges and corners [126]. However, it is not clear whether carbon resides on the surface or might penetrate into the subsurface region as predicted theoretically [127]. This effect demonstrates the exceptional importance of carbon for the olefin hydrogenation, which can be carried out in a truly catalytic fashion for many turnovers, only on C-containing Pd nanoparticles.

The role of carbon in promotion of sustained hydrogenation was rationalized by employing transient molecular beam experiments and resonant nuclear reaction analysis (rNRA) for hydrogen depth profiling. First, we obtained a direct experimental evidence that the presence of $H(D)$ adsorbed in the Pd particle volume is required for olefin hydrogenation, particularly for the second half-hydrogenation step of the Horiuti-Polanyi mechnism [128], in agreement with previous experimental evidences [129]. This result explains the high initial hydrogenation rates, observed on the clean particles fully saturated with $\mathrm{D}$, and vanishing hydrogenation activity in steady states because of the depletion of the subsurface D reservoir (Figure 24(a)). Apparently, the inability to populate subsurface D sites arises from the hindered D subsurface diffusion through the surface covered with hydrocarbons. Further, it was shown that even a sub-monolayer coverage of carbon significantly affects the H(D) depth distribution in Pd particles [128]. Based on these observations and on the analysis of the hydrogenation kinetics [130], we attribute the sustained hydrogenation activity to the facilitation of H(D) diffusion into the particle volume by the deposited carbon. Theoretical studies confirm those ideas [131].

Finally, we provided direct experimental evidences for a faster subsurface $\mathrm{H}$ diffusion through $\mathrm{C}$-modified low-coordinated surface sites on Pd nanoparticles by probing the 


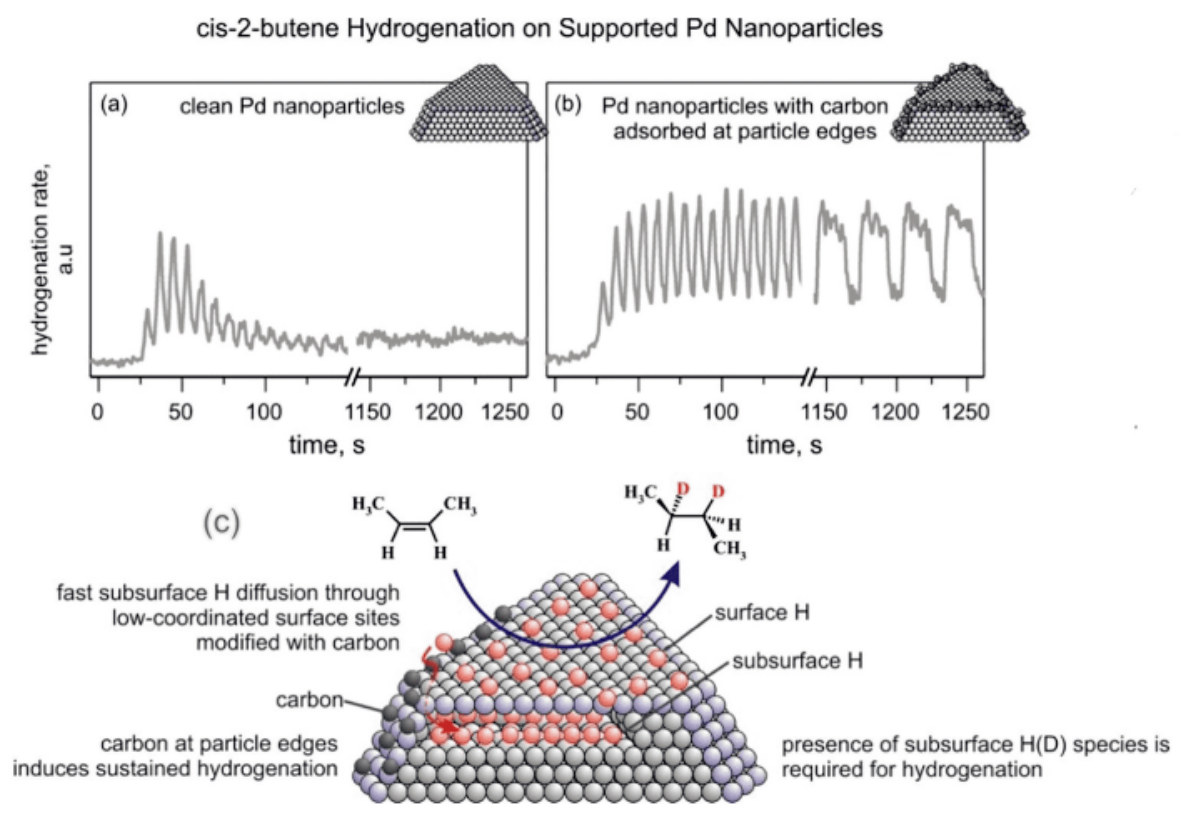

Figure 24 Hydrogenation rate of cis-2-butene at $260 \mathrm{~K}$ over clean (a) and C-precovered (b) model catalysts $\mathrm{Pd} / \mathrm{Fe}_{3} \mathrm{O}_{4} / \mathrm{Pt}(111)$. (c) $\mathrm{Proposed}$ reaction mechanism of olefin hydrogenation on Pd nanoparticles, adapted with permission from Ref. [133], copyright by American Chemical Society (2015) (color online).

diffusion rate via $\mathrm{H}_{2}+\mathrm{D}_{2} \rightarrow \mathrm{HD}$ exchange in different temperature regimes [132]. It was previously shown [126] that the formation of HD can occur either via recombination of two surface $\mathrm{H}$ and $\mathrm{D}$ species or an involvement of subsurface $\mathrm{H}$ or D species. The latter pathway dominates at low temperatures between 200 and $300 \mathrm{~K}$. Our experimental results are consistent with the scenario implying that one subsurface atom ( $\mathrm{H}$ or $\mathrm{D})$ recombines with a surface-adsorbed atom to form HD. In the case of the slow subsurface H(D) diffusion, the formation rate of subsurface species will be the limiting step in HD production, and can, therefore, be addressed by probing the rate of isotopic scrambling.

We now move to the second example concerning with $\mathrm{CO}_{2}$ activation on raft $\mathrm{Au}$ particles on $\mathrm{MgO}(100)$ in view of the charge transfer observed in those systems. Only very recently Calaza et al. [134] were able to record and image $\mathrm{CO}_{2}$ reactivity at the rim of two-dimensional $\mathrm{Au}$ rafts on $\mathrm{MgO}$ (100). As depicted in Figure 25, in this study two important factors were exploited. On the one hand, the morphology (flat raft) of the pristine nanoparticle (Figure 25(a)) has been instrumentalized, which allows us to access the perimeter in detail, and on the other hand, we make use of the pronounced electron transfer towards the $\mathrm{Au}$ atoms residing at the perimeter, which may be used to induce chemical reactions. In the present case, $\mathrm{CO}_{2}$ has been used as a reactant. Figure 25 (b) shows the $\mathrm{Au}$ nano-particle decorated with adsorbed species at its perimeter, and the differential conductance spectroscopic image shown in Figure 25(c) clearly reveals the increased electron density at the nanoparticle rim. $\mathrm{CO}_{2}$ is a thermodynamically very stable molecule if no electrons are present. In the presence of electrons, $\mathrm{CO}_{2}$ is activated by the electron transfer. In the present case oxalate $\mathrm{C}_{2} \mathrm{O}_{4}{ }^{2-}$ is formed at the rim of the $\mathrm{Au}$ raft, where we noted above the high electron density. The nature of the created species is confirmed by ensemble averaging IRAS, including isotopic labeling studies. When one investigates the distribution of oxalate molecules along the perimeter one finds inhomogeneities that may be connected to the above-mentioned inhomogeneous distribution of extra electrons along the perimeter. Additional IETS measurements may allow to reveal the exact nature of individual molecular species and their formation. In addition, Figure 25 reveals differences of the quantum well states in a naked $\mathrm{Au}$ island and islands with the oxalate adsorbed, as probed with $\mathrm{d} I / \mathrm{d} V$ spectroscopy. Notably, the energetic position of the quantum well states changes, indicating that the presence of the negatively charged molecules at the rim constrains the Au 6s electrons to a smaller area, thus shifting the quantum well states to higher energy. The study is aimed to provide a conceptual insight into a way on how to trigger charge-transfer driven reactions, and yet one may argue that the thin-film model systems are not suitable for the direct use in real heterogeneous catalysis. However, one may create a similar situation with respect to charge transfer also in real powder catalysts by employing the concept of doping, as we had demonstrated above.

A third and final example of studying supported metal model catalysts, presented in this review, deals with a phenomenon, the catalysis community called "Strong Metal Support Interaction". This phenomenon is commonly associated with the encapsulation of supported metal nano-particles on reducible oxides by a thin oxide layer of support 

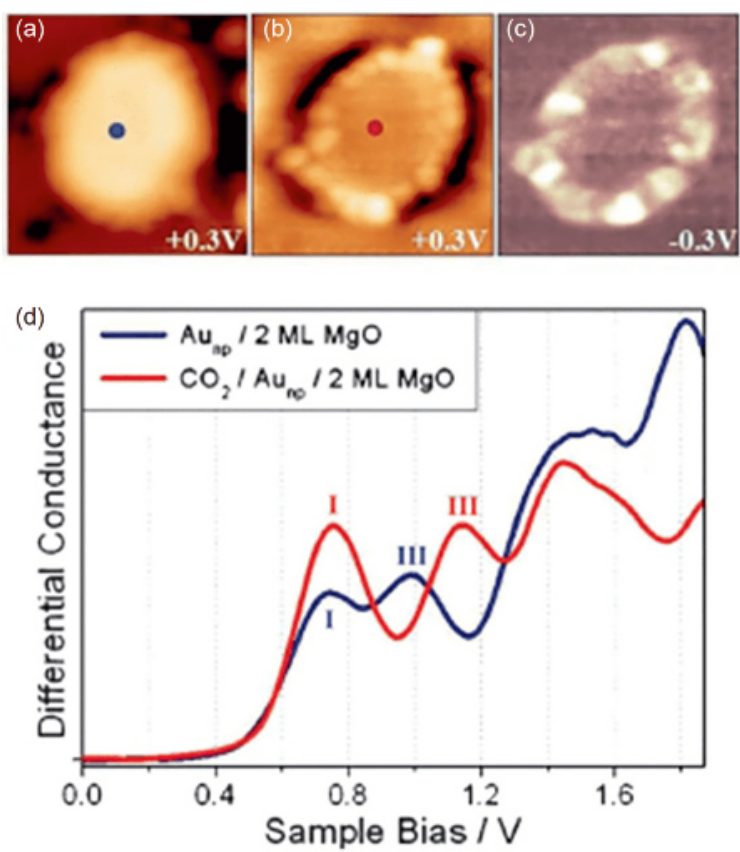

Figure 25 STM topographic images of (a) a pristine planar Au cluster and (b) after exposure to $\mathrm{CO}_{2}$, (scan size $8.0 \mathrm{~nm} \times 8.0 \mathrm{~nm}, 50 \mathrm{pA}$ ). The $\mathrm{Au}$ clusters were prepared by evaporating $\mathrm{Au}$ on $\mathrm{MgO}$ mono- or $b i$-layer films at $300 \mathrm{~K}$. Subsequently the sample was exposed to $10-15 \mathrm{~L} \mathrm{CO}_{2}$ in a temperature range from $220-250 \mathrm{~K}$. Molecules at the cluster perimeter in (b) become visible only when scanning at bias voltages between -0.5 and $+0.5 \mathrm{~V}$. (c) Corresponding $\mathrm{d} I / \mathrm{d} V$ map, displaying the high localization of electron density at the negatively charged cluster rim. (d) $\mathrm{d} I / \mathrm{d} V$ spectra taken at the center of the clusters shown in (a) (blue) and (b) (red). The positions of the first (I) and third (III) quantum well state in both spectra are indicated. Note the energy shift towards higher energy of the internal energy scale of the cluster which is compatible with a $\mathrm{CO}_{2}$ induced decrease of the electron potential well formed by the Au island, adapted with permission from Ref. [134], copyright by John Wiley and Sons (2015) (color online). materials. It was first observed for $\mathrm{Pt}$ on $\mathrm{TiO}_{2}$ [135], but we have concentrated on the case of Pt on magnetite $\mathrm{Fe}_{3} \mathrm{O}_{4}(111)$, because it was shown by high resolution STM and TEM under reducing conditions that the iron oxide layer overgrowing the $\mathrm{Pt}$ particle is a well-ordered $\mathrm{FeO}(111)$ film, which had been previously well characterized on Pt(111) [136]. A number of groups have looked into the reactivity of a "monolayer" $\mathrm{FeO}(111)$ film on $\mathrm{Pt}(111)$ with respect to $\mathrm{CO}$ oxidation [137]. Experimental studies and density functional theory (DFT) calculations [138] showed that a $\mathrm{FeO}(111)$ film transforms into an O-rich film with a close to $\mathrm{FeO}_{2}$ stoichiometry and $\mathrm{O}-\mathrm{Fe}-\mathrm{O}$ tri-layer composition. In fact, the Orich films have a more complex structure, schematically shown in Figure 26, where $\mathrm{FeO}_{2}$ tri-layer domains are likely embedded into the $\mathrm{FeO}$ film following the long range Moiré pattern initially present in $\mathrm{FeO}(111) / \mathrm{Pt}(111)[139,140]$. The $\mathrm{CO}$ oxidation mechanism was first rationalized in terms of the direct $\mathrm{CO}$ reaction with a more weakly bound oxygen atom in the topmost layer. The process yields a $\mathrm{CO}_{2}$ molecule that desorbs and leaves an oxygen vacancy behind, which is then replenished by reactions with molecular $\mathrm{O}_{2}$ from the gas-phase. The situation becomes more complex for partially covered Pt(111) surfaces when oxide/metal interfacial sites have to be considered as well. Bao and coworkers [141] showed that under UHV conditions the edges of $\mathrm{FeO}(111)$ $b i$-layer islands are active in $\mathrm{CO}$ oxidation. However, under near atmospheric pressure conditions the $\mathrm{FeO}_{2-x}$ films inevitably form, and the active sites must include the $\mathrm{FeO}_{2-x}$ rather than edge sites. Moreover, the interface sites between the $\mathrm{FeO}$ bilayer and the $\mathrm{FeO}_{2}$ trilayer domains must also be considered [142]. The latter conclusion has been drawn from the observations summarized in Figure 26. STM image (a)
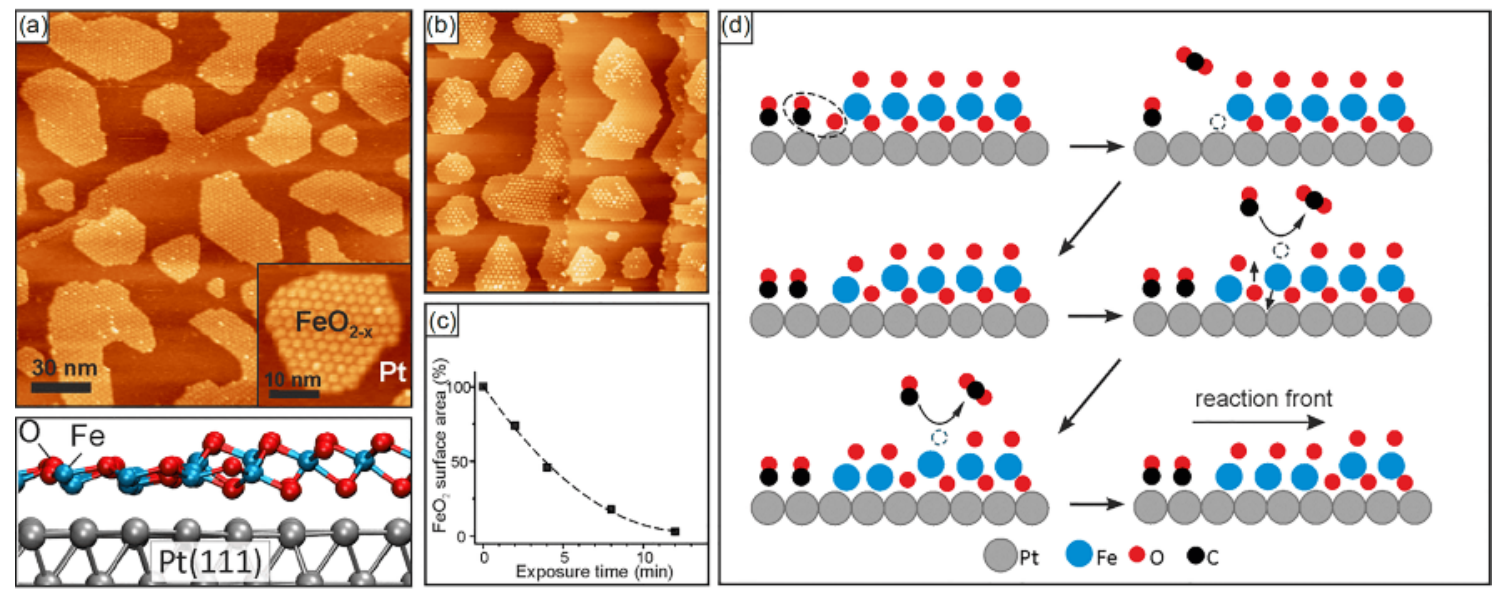

Figure 26 (a) Typical morphology of oxidized $\mathrm{FeO}_{2-x}$ films on $\mathrm{Pt}(111)$ at sub-monolayer coverages. The cross-view of a FeO $\mathrm{F}_{2-x} / \mathrm{Pt}(111)$ film is shown below. (b) STM images of $0.5 \mathrm{ML} \mathrm{FeO}_{2-x} / \mathrm{Pt}(111)$ film exposed to $10^{-6}$ mbar CO at $450 \mathrm{~K}$ for 4 min (Image size is $150 \mathrm{~nm} \times 150 \mathrm{~nm}$; tunneling bias and current are $-3 \mathrm{~V}$ and $0.1 \mathrm{nA}$, respectively). (c) The $\mathrm{FeO}_{2-x}$ surface area normalized to the area in the "as prepared" sample as a function of the exposure time. (d) Schematic scenario for $\mathrm{CO}$ reactions with $\mathrm{FeO}_{2-x} / \mathrm{Pt}(111)$ islands. $\mathrm{CO}$ adsorbed on $\mathrm{Pt}$ reacts with the $\mathrm{O}$ atom at the island edge to form $\mathrm{CO}_{2}$. The atoms surrounding the $\mathrm{O}$ vacancy relax and locally form a $\mathrm{FeO}$ bilayer structure. Further reaction occurs at the interface between the original oxidized $\mathrm{FeO}_{2}$ and the reduced FeO-like phases, providing the weakest bonded oxygen, adapted with permission from Ref. [142], copyright by John Wiley and Sons (2018) (color online). 
shows a typical morphology of sub-monolayer $\mathrm{FeO}_{2-x}$ films. The $\mathrm{FeO}_{2}$ regions are identified by the bright protrusions, and it is obvious from the image in the inset that the entire island is covered by a $\mathrm{FeO}_{2-x}$ tri-layer. A situation encountered after exposure to $\mathrm{CO}$ at $10^{-6} \mathrm{mbar}$ at $450 \mathrm{~K}$ is shown in Figure 26(b). The $\mathrm{FeO}_{2-x}$ covered area is reduced, obviously from the island edge towards the island center. In fact, as Figure 26(c) suggests, the $\mathrm{FeO}_{2-x}$ area is reduced as a function of $\mathrm{CO}$ exposure time. Such a decay is typical for etching of 2D-islands involving the reaction at the edge sites following a first order kinetics. On the basis of those and further kinetic measurements we have proposed that the reaction of $\mathrm{CO}$ with $\mathrm{O}$ in $\mathrm{FeO}_{2-x}$ islands starts at the island rim and then propagates as depicted in Figure 26(d). For simplicity, we consider the exposed $\mathrm{FeO}_{2} /$ metal interface. First, $\mathrm{CO}$ adsorbed on $\mathrm{Pt}$ reacts with the $\mathrm{O}$ atom at the island edge. The $\mathrm{Fe}$ atoms around the $\mathrm{O}$ vacancy relax and bind to $\mathrm{Pt}$ locally forming a FeO-like structure. However, the further $\mathrm{CO}$ reaction with the oxide edge is hardly possible under these assumptions, as it requires about $2.15 \mathrm{eV}$ to extract oxygen from the lattice. Therefore, the reaction pathway involving $\mathrm{CO}$ on $\mathrm{Pt}(111)$ is terminated. However, a new interface is created, which is somewhat similar to the "intrinsic" $\mathrm{FeO} / \mathrm{FeO}_{2}$ interface (Figure 26(e)). As we know from DFT calculations the extraction of oxygen at this interface only costs $1.31 \mathrm{eV} \mathrm{[143],} \mathrm{thus} \mathrm{rendering} \mathrm{the} \mathrm{reaction} \mathrm{with}$ $\mathrm{CO}$ easier than that at the intact film surfaces. The present example is one of the very cases, where an oxide-oxide interface is relevant.

\subsection{Approaching modelling wet impregnation of sup- ported metal catalysts}

The investigations discussed so far were limited to systems studied under UHV conditions which immediately poses the question how these results relate to oxide systems at ambient conditions such as an aqueous environment. In the following we illustrate how such well-defined systems prepared under UHV conditions can be used to study the properties of the oxide surfaces under ambient conditions.

A variety of technologically important processes, such as catalyst preparation by wet impregnation, involve processes at the liquid/oxide interface. Aiming at the investigation of such processes using well-defined thin oxide films the system has to be stable under the specific environmental conditions of interest. Here the $\mathrm{pH}$ plays a particularly important role. For surface science investigations in particular, it is desirable that the structural order is maintained. Since the chemical properties of (most) oxide thin films are similar as those of the corresponding bulk analogues, their stability and dissolution behavior are expected to follow the same trends. Dissolution rates for oxide thin film samples can be derived from the measured decrease of film thickness upon exposure to aqueous solution, which can straightforwardly be determined from the intensities of the oxide and substrate XPS or AES emissions.

Iron oxides are stable in aqueous solutions in a wide range of $\mathrm{pH}$. Thus, it is not surprising that also thin iron oxide films are very stable in aqueous solutions. STM images (Figure 27 (a)) taken in air from $\mathrm{Fe}_{3} \mathrm{O}_{4}(111) / \mathrm{Pt}(111)$ films which have been prepared in UHV and subsequently transferred to air ambient and exposed to aqueous solutions $(\mathrm{pH} 1,0.1 \mathrm{M} \mathrm{HCl}$ and $\mathrm{pH} 10, \mathrm{NaOH}_{\mathrm{aq}}$ ) for $1 \mathrm{~h}[144,145]$, reveal that the islandterrace-step structure of the thin film remains intact. Furthermore, the step edges run straight along the crystallographic preferred directions and the terraces are atomically flat. The first step in a commonly applied wet-chemical catalyst preparation procedure consists of the interaction of the support with precursor solutions that contain the metal component in the form of salts or complexes. This is followed by drying, calcination and reduction steps, which are necessary to transform the adsorbed metal precursor into the catalytically active phase. With $\mathrm{Fe}_{3} \mathrm{O}_{4}(111) / \mathrm{Pt}(111)$ as a support, the preparation of supported Pd nanoparticles using $\mathrm{PdCl}_{2}$ as a precursor has been studied [144,145].

An important question to ask at this point is whether or not the morphology of a model catalyst prepared by wet-chemical procedures as described above differs from that of a corresponding model catalyst prepared exclusively in UHV. In other words, does the nature of the precursor (single atoms

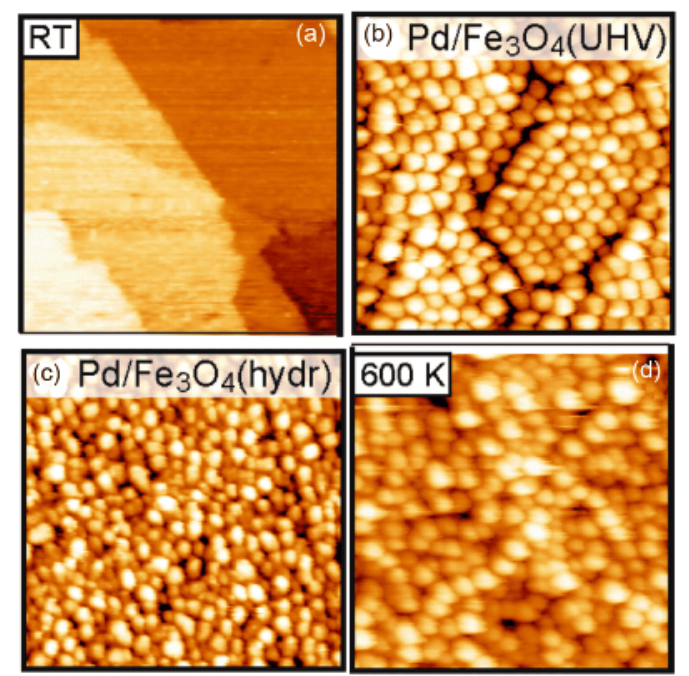

Figure 27 (a) STM image $(100 \mathrm{~nm} \times 100 \mathrm{~nm})$ of a $\mathrm{Fe}_{3} \mathrm{O}_{4}(111) / \mathrm{Pt}(111)$ thin film surface acquired in air after preparation in UHV after exposure to $\mathrm{Pd}$ precursor solution ( $5 \mathrm{mM} \mathrm{PdCl}_{2}, \mathrm{pH} \mathrm{10)}$ and subsequent drying (RT), and subsequent heating to $600 \mathrm{~K}$. (b) STM image $(100 \mathrm{~nm} \times 100 \mathrm{~nm})$ of $\mathrm{Pd} /$ $\mathrm{Fe}_{3} \mathrm{O}_{4}(111)$ prepared by physical vapor deposition of Pd in UHV. (c) STM image $(100 \mathrm{~nm} \times 100 \mathrm{~nm})$ of $\mathrm{Pd} / \mathrm{Fe}_{3} \mathrm{O}_{4}(111)$ prepared by physical vapor deposition of $\mathrm{Pd}$ onto a $\mathrm{Fe}_{3} \mathrm{O}_{4}(111)$ surface modified by treatment with $\mathrm{NaOH}$ solution. (d) STM image of a $\mathrm{Fe}_{3} \mathrm{O}_{4}(111) / \mathrm{Pt}(111)$ thin film surface acquired after exposure to $\mathrm{Pd}$ precursor solution $\left(5 \mathrm{mM} \mathrm{PdCl}_{2}, \mathrm{pH} 10\right)$ and subsequent drying (RT), and subsequent heating to $600 \mathrm{~K}$, adapted with permission from Ref. [146], copyright by Springer Nature (2016) (color online). 
in UHV vs. metal complexes in solution) or the support properties (clean surface in UHV vs. a surface modified by exposure to precursor solution) affect the properties of the activated model catalyst? In order to answer this question two $\mathrm{Pd} / \mathrm{Fe}_{3} \mathrm{O}_{4}(111)$ model catalysts were prepared: one, where $\mathrm{Pd}$ was deposited onto a clean $\mathrm{Fe}_{3} \mathrm{O}_{4}(111)$ support in UHV by vapor deposition $\left(\mathrm{Pd} / \mathrm{Fe}_{3} \mathrm{O}_{4}(\mathrm{UHV})\right.$, Figure $\left.27(\mathrm{~b})\right)$, and another one, where Pd was deposited by vapor deposition onto a $\mathrm{Fe}_{3} \mathrm{O}_{4}(111)$ surface following a treatment with $\mathrm{NaOH}(\mathrm{pH} 12)$ solution $\left(\mathrm{Pd} / \mathrm{Fe}_{3} \mathrm{O}_{4}(\right.$ hydr), Figure 27(c)). The $\mathrm{NaOH}$ treatment was applied in order to achieve a surface functionality comparable to the solution deposition experiment. Inspecting the corresponding STM images (Figure 27 $(b, c))$ reveals differences between the two samples with respect to the arrangement of the Pd particles and the particle size distribution. While the Pd particles are uniform in size and arranged in an almost perfect hexagonal array on the clean $\mathrm{Fe}_{3} \mathrm{O}_{4}(111)$ surface, the surface order is lost on the pretreated $\mathrm{Fe}_{3} \mathrm{O}_{4}$ surface and a deviation from the normal particle size distribution is apparent. Most notably, the morphology of the vapor deposited $\mathrm{Pd} / \mathrm{Fe}_{3} \mathrm{O}_{4}$ (hydr) sample (Figure 27(c)) closely resembles that of the model catalyst prepared by the deposition of Pd from the precursor solution at $\mathrm{pH} 10$ (Figure 27(d)). This finding suggests that in the present case the morphology of the activated model catalyst is mainly governed by the interfacial properties, and not by the nature of the precursor. The more heterogeneous sintering of Pd particles on the modified surfaces is attributed to

(a)

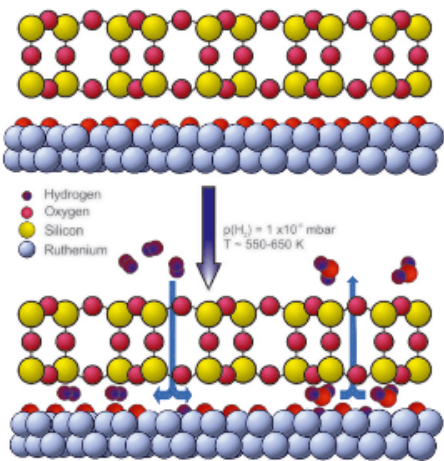

(c)
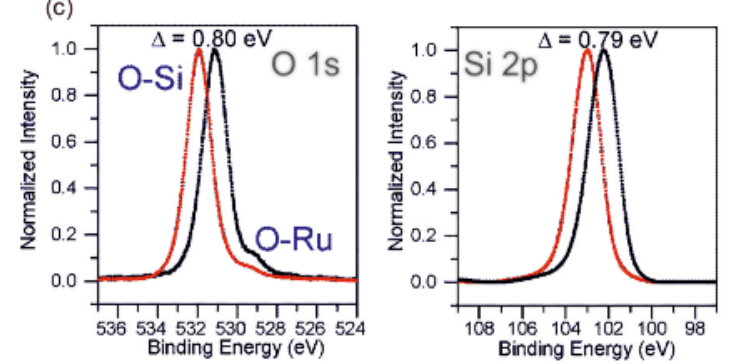

the presence of hydroxyl groups and the existence of a variety of adsorption sites with differing Pd adhesion properties [145].

\subsection{Reactions in confined space}

As a brief remark to close the discussion on model catalysts we refer to some recent studies on reactions in a confined space [147]. Confined space reactions play a very important role in the zeolite chemistry but are also presumed to be important in questions connected with the origin of life. The Fu group at Dalian Institute of Chemical Physics, Chinese Academy of Sciences, has looked at reactions underneath graphene and has recently reviewed the activities in this field [148]. There are studies in confined systems such as nanotubes and similar systems [149]. We have studied the reaction of water formation underneath the silica film [147] discussed in Sect. 3.1. To this end, we intercalate oxygen on the $\mathrm{Ru}(0001)$ surface and then diffuse $\mathrm{H}_{2}$ through the pores of the silica film to react with the oxygen to form water (Figure 28(a)). The same reaction has been studied long ago by the Menzel's group [150] on the bare, i.e., not $\mathrm{SiO}_{2}$ covered $\mathrm{Ru}(0001)$ surface. The point here is that a fully oxygen covered $\mathrm{Ru}(0001)$ surface does not dissociate molecular hydrogen, so that a reaction can only start at areas where the oxygen coverage is lower. This actually leads to the formation of a reaction front, which we have been able to observe with the LEEM/PEEM instrument mentioned above.

(b)
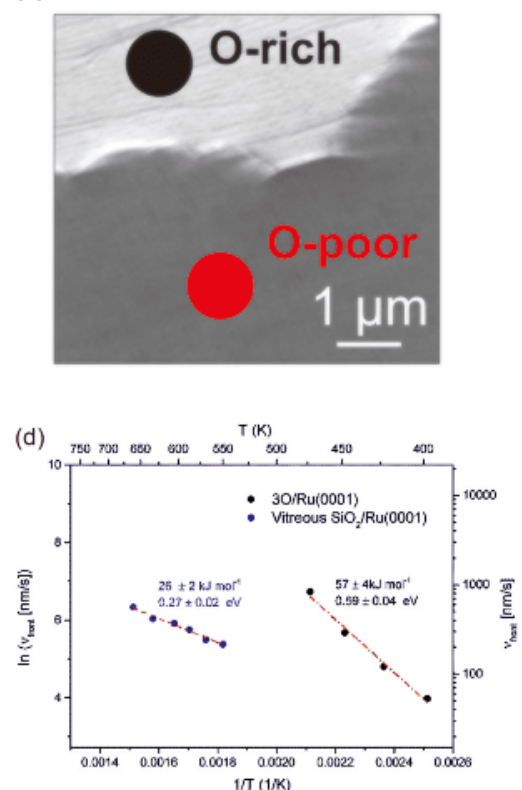

Figure 28 (a) Representation of the system used to study the water formation reaction in the confined space under a vitreous $\mathrm{SiO}_{2}$ bilayer supported on $\mathrm{Ru}$ (0001). (b) LEEM image of the reaction front recorded at room temperature on the $\mathrm{H}_{2}$-treated $\mathrm{SiO}_{2}$ vitreous $\mathrm{BL}$ on $\mathrm{Ru}(0001$ ). (c) $\mathrm{O} 1 \mathrm{~s}$ and $\mathrm{Si} 2 \mathrm{p} \mathrm{XPS}$ spectra collected after $\mathrm{H}_{2}$ treatment. $\mathrm{O} 1 \mathrm{~s}$ and $\mathrm{Si} 2 \mathrm{p}$ lines were measured with $600 \mathrm{eV}$ photon energy on the areas indicated in (b). (d) Arrhenius plots of the temperature-dependent velocities of the reaction front on $\mathrm{SiO}_{2} / \mathrm{Ru}(0001)$ (blue dots) and 3O/Ru(0001) (black dots) [147], adapted with permission from Ref. [147], copyright by John Wiley and Sons (2018) (color online). 
Figure 28(b) shows an image of the reaction front, where the bright areas are the oxygen rich and the darker areas the oxygen poor areas. The option to use local XPS verifies the claim, as the Ru oxygen peak is missing on the oxygen poor area (Figure 28(c)). The observed peak shifts are connected with the variations of the surface potential. From the motion of the reaction front as a function of temperature an Arrhenius plot provides access to the apparent activation energy (Figure 28(d)). If we compare the value of $26 \mathrm{~kJ} / \mathrm{mol}$ with the value of about $60 \mathrm{~kJ} / \mathrm{mol}$ (a very similar value has been reported by Menzel and coworkers) [150] for the same reaction in an open space we note a factor of about 2 between the apparent activation energies. Textbooks suggest this to be the sign of diffusion control [151]. We undertook a detailed analysis including theoretical calculations on the potential energy hypersurface for the entire reaction in the confined and open space, and confirm that diffusion control is important, but the details are important to be considered. In consequence, we believe, that surface science may also contribute important knowledge to areas, such as confined space reactions, where it was not expected.

\section{Conclusions}

The purpose of the review was to demonstrate that surface science is far from being dead! Model studies in heterogeneous catalysis, we sincerely believe, may provide a conceptual insight into fundamental questions that are very difficult to acquire otherwise. We have discussed the development of innovative experimental techniques, which is important, if one wants to address new questions, and showed how those may be applied. We have covered an approach that systematically increases complexity in the model systems in order to approach a description of the real catalytic material. We have proposed some novel concepts that may be used to develop and design novel catalytic materials for further applications. The attempt was made to bridge not only the materials gap by designing models of increasing complexity, but also by trying to connect to the typically applied preparation techniques in heterogeneous catalysis. Last but not least, we pointed out a way to approach the study of reactions in the confined space, which may open up avenues to contribute to our understanding of reactions in cavities. It should have also become obvious that we can only bring the science of catalysis forward if we think of novel instrumentation to address the open questions. This is particularly important when we consider to bridge not only the materials but also the pressure gap. Near ambient pressure techniques in the photoelectron spectroscopy and photoabsorption based on the availability of synchrotron radiation to some extent lead the way in this direction. Along the same line the developments of scanning probe techniques working at ambient pressures or at the liquid solid interface are important directions, too. But these cannot be the end of it. New ideas are in need!

Acknowledgements This work was supported by the Federal German Ministry of Education and Science (BMBF) (05KS4WWB/4), the Deutsche Forschungsgemeinschaft through CRC 1109 ("Molecular Insight into Metaloxide/Water Interfaces"), CRC 546 ("Structure and Reactivity of Transition Metal Oxides"), the DFG-NSFC joint project (Fr554/18-1, 21761132005), and Cluster of Excellence "UniCat", as well as the Fonds der Chemischen Industrie and TURBOMOLE GmbH. This project has received funding from the European Research Council (ERC) under the European Union's Horizon 2020 Research and Innovation Program (CRYVISIL-REP669179). We would like to thank all former and present postdoctoral associates as well as $\mathrm{PhD}$ students involved in the projects mentioned. In particular we thank Professor Weixin Huang/USTC for discussions. We thank the BESSY II crew for their support and the Helmholtz-Center Berlin for Materials and Energy (HZB) for the allocation of beamtime.

Funding note Open access funding provided by Projekt DEAL.

Conflict of interest The authors declare that they have no conflict of interest.

Open Access This article is licensed under a Creative Commons Attribution 4.0 International License, which permits use, sharing, adaptation, distribution and reproduction in any medium or format, as long as you give appropriate credit to the original author(s) and the source, provide a link to the Creative Commons licence, and indicate if changes were made. The images or other third party material in this article are included in the article's Creative Commons licence, unless indicated otherwise in a credit line to the material. If material is not included in the article's Creative Commons licence and your intended use is not permitted by statutory regulation or exceeds the permitted use, you will need to obtain permission directly from the copyright holder. To view a copy of this licence, visit http://creativecommons.org/licenses/by/4.0/.

1 Ertl G, Knözinger H, Schueth F, Weitkamp J. Handbook of Heterogeneous Catalysis. Weinheim: VCH, 2008

2 Schlögl R. Angew Chem Int Ed, 2015, 54: 3465-3520

3 Freund HJ. Angew Chem Int Ed Engl, 1997, 36: 452-475

4 Haber F, Le Rossignol R. Z für Elektrochem, 1913, 19: 53-72

5 Mittasch A. Geschichte der Ammoniaksynthese. Verlag Chemie: Berlin-Weinheim, 1951

6 Drauglis E, Jaffee RI. The physical basis for heterogeneous catalysis. in: Battelle Institute Materials Science Colloquia. New York: Springer, 1975

7 Ertl G. Angew Chem Int Ed Engl, 1990, 29: 1219-1227

8 Mittasch A. Einiges über Mehrstoffkatalysatoren. Elektrochem Z, 1930, 36: 569-580

9 Schlögl R. Angew Chem Int Ed, 2003, 42: 2004-2008

10 Chakrabarti A, Ford ME, Gregory D, Hu R, Keturakis CJ, Lwin S, Tang Y, Yang Z, Zhu M, Bañares MA, Wachs IE. Catal Today, 2017, 283: $27-53$

11 Freund HJ. J Am Chem Soc, 2016, 138: 8985-8996

12 Sauer J, Freund HJ. Catal Lett, 2015, 145: 109-125

13 Freund H-J, Heyde M, Kuhlenbeck H, Nilius N, Risse T, Schauermann S, Schmidt T, Shaikhutdinov S, Sterrer M. in: Rocca M, Ed. Handbook of Surface Science. New York: Springer, in press

14 Freund HJ, Nilius N, Risse T, Schauermann S, Schmidt T. ChemPhysChem, 2011, 12: 79-87

15 Faisal F, Bertram M, Stumm C, Waidhas F, Brummel O, Libuda J. Rev Sci Instruments, 2018, 89: 114101

16 Dou J, Sun Z, Opalade AA, Wang N, Fu W, Tao FF. Chem Soc Rev, 2017, 46: 2001-2027 
17 van Spronsen MA, Frenken JWM, Groot IMN. Chem Soc Rev, 2017, 46: 4347-4374

18 Salmeron M, Schlögl R. Surf Sci Rep, 2008, 63: 169-199

19 Schmidt T, Groh U, Fink R, Umbach E, Schaff O, Engel W, Richter B, Kuhlenbeck H, Schlögl R, Freund HJ, Bradshaw AM, Preikszas D, Hartel P, Spehr R, Rose H, Lilienkamp G, Bauer E, Benner G. Surf Rev Lett, 2002, 9: 223-232

20 Schmidt T, Marchetto H, Lévesque PL, Groh U, Maier F, Preikszas D, Hartel P, Spehr R, Lilienkamp G, Engel W, Fink R, Bauer E, Rose H, Umbach E, Freund HJ. Ultramicroscopy, 2010, 110: 1358-1361

21 Fink R, Weiss MR, Umbach E, Preikszas D, Rose H, Spehr R, Hartel P, Engel W, Degenhardt R, Wichtendahl R, Kuhlenbeck H, Erlebach W, Ihmann K, Schlögl R, Freund HJ, Bradshaw AM, Lilienkamp G, Schmidt T, Bauer E, Benner G. J Electron Spectr Related Phenomena, 1997, 84: 231-250

22 Schmidt T, Sala A, Marchetto H, Umbach E, Freund HJ. Ultramicroscopy, 2013, 126: 23-32

23 Schlienz H, Beckendorf M, Katter UJ, Risse T, Freund HJ. Phys Rev Lett, 1995, 74: 761-764

24 Farle M, Zomack M, Baberschke K. Surf Sci, 1985, 160: 205-216

25 Rocker J, Cornu D, Kieseritzky E, Seiler A, Bondarchuk O, HänselZiegler W, Risse T, Freund HJ. Rev Sci Instrum, 2014, 85: 083903

26 Cornu D, Rocker J, Gonchar A, Risse T, Freund HJ. Phys Rev Lett, 2016, 117: 016801

27 Wu Z, Płucienik A, Feiten FE, Naschitzki M, Wachsmann W, Gewinner S, Schöllkopf W, Staemmler V, Kuhlenbeck H, Freund HJ. Phys Rev Lett, 2017, 119: 136101

28 Wu Z, Płucienik A, Liu Y, Naschitzki M, Wachsmann W, Gewinner S, Schöllkopf W, Kuhlenbeck H, Freund HJ. Rev Sci Instrum, 2018, 89: 083107

29 Simard B, Dénommée S, Rayner DM, Heijnsbergen D, Meijer G, Helden G. Chem Phys Lett, 2002, 357: 195-203

30 Asmis KR. Phys Chem Chem Phys, 2012, 14: 9270-9281

31 Jaeger RM, Kuhlenbeck H, Freund HJ, Wuttig M, Hoffmann W, Franchy R, Ibach H. Surf Sci, 1991, 259: 235-252

32 Kulawik M, Nilius N, Rust HP, Freund HJ. Phys Rev Lett, 2003, 91: 2561011-2561014

33 Schintke S, Messerli S, Pivetta M, Patthey F, Libioulle L, Stengel M, De Vita A, Schneider WD. Phys Rev Lett, 2001, 87: 27680112768014

34 Pal J, Smerieri M, Celasco E, Savio L, Vattuone L, Rocca M. Phys Rev Lett, 2014, 112: 126102

35 Pal J, Smerieri M, Celasco E, Savio L, Vattuone L, Ferrando R, Tosoni S, Giordano L, Pacchioni G, Rocca M. J Phys Chem C, 2014, 118: 26091-26102

36 Nilius N, Sterrer M, Heyde M, Freund H-J. Atomic scale characterization of defects on oxide surfaces. in: Jupille J, Thornton G, Eds. Defects at Oxide Surfaces. Cham: Springer International Publishing, 2015. 29-80

37 Benedetti S, Benia HM, Nilius N, Valeri S, Freund HJ. Chem Phys Lett, 2006, 430: 330-335

38 Benedetti S, Torelli P, Valeri S, Benia HM, Nilius N, Renaud G. Phys Rev B, 2008, 78: 195411-195418

39 Sterrer M, Heyde M, Novicki M, Nilius N, Risse T, Rust HP, Pacchioni G, Freund HJ. $J$ Phys Chem B, 2006, 110: 46-49

40 Konig T, Simon GH, Rust HP, Pacchioni G, Heyde M, Freund HJ. $J$ Am Chem Soc, 2009, 131: 17544-17545

41 Sterrer M, Fischbach E, Risse T, Freund HJ. Phys Rev Lett, 2005, 94 : 186101

42 Gonchar A, Risse T, Freund HJ, Giordano L, Di Valentin C, Pacchioni G. Angew Chem Int Ed, 2011, 50: 2635-2638

43 Grzybowska-Swierkosz B, Trifiro F, Appl Catal A: Gen, 1997, 157: $1-2$

44 Surnev S, Ramsey MG, Netzer FP. Prog Surf Sci, 2003, 73: 117-165

45 Chieregato A, López Nieto JM, Cavani F. Coord Chem Rev, 2015, 301: 3-23

46 Jiang BB, Yuan SL, Chen N, Wang HB, Wang JD, Huang ZL. Cataly
Prog Chem, 2015, 27: 1679-1688

47 Sutradhar M, Martins LMDRS, Guedes da Silva MFC, Pombeiro AJL. Coord Chem Rev, 2015, 301: 200-239

48 Artiglia L, Agnoli S, Granozzi G. Coord Chem Rev, 2015, 301: 106122

49 Carrero CA, Schloegl R, Wachs IE, Schomaecker R. ACS Catal, 2014, 4: 3357-3380

50 Kuhlenbeck H, Shaikhutdinov S, Freund HJ. Chem Rev, 2013, 113: 3986-4034

51 Guimond S, Göbke D, Romanyshyn Y, Sturm JM, Naschitzki M, Kuhlenbeck H, Freund HJ. J Phys Chem C, 2008, 112: 1236312373

52 Guimond S, Sturm JM, Göbke D, Romanyshyn Y, Naschitzki M, Kuhlenbeck H, Freund HJ. J Phys Chem C, 2008, 112: 11835-11846

53 Feiten FE, Kuhlenbeck H, Freund HJ. J Phys Chem C, 2015, 119: 22961-22969

54 Feiten FE, Seifert J, Paier J, Kuhlenbeck H, Winter H, Sauer J, Freund HJ. Phys Rev Lett, 2015, 114: 216101

55 Dupuis AC, Abu Haija M, Richter B, Kuhlenbeck H, Freund HJ. Surf Sci, 2003, 539: 99-112

56 Schoiswohl J, Sock M, Surnev S, Ramsey MG, Netzer FP, Kresse G, Andersen JN. Surf Sci, 2004, 555: 101-117

57 Window AJ, Hentz A, Sheppard DC, Parkinson GS, Niehus H, Ahlbehrendt D, Noakes TCQ, Bailey P, Woodruff DP. Phys Rev Lett, 2011, 107: 016105

58 Niehus H, Blum RP, Ahlbehrendt D. Surf Rev Lett, 2003, 10: 353359

59 Tepper B, Richter B, Dupuis AC, Kuhlenbeck H, Hucho C, Schilbe P, bin Yarmo MA, Freund HJ. Surf Sci, 2002, 496: 64-72

60 Atrei A, Bardi U, Tarducci C, Rovida G. J Phys Chem B, 2000, 104: 3121-3129

61 Atrei A, Bardib U, Cortigiani B, Rovida G. Surf Rev Lett, 1999, 6: $1187-1193$

62 Romanyshyn Y, Guimond S, Göbke D, Sturm JM, Kuhlenbeck H, Döbler J, Ganduglia-Pirovano MV, Sauer J, Freund HJ. Top Catal, 2011, 54: 669-684

63 Tasker PW. J Phys C-Solid State Phys, 1979, 12: 4977-4984

64 Window AJ, Hentz A, Sheppard DC, Parkinson GS, Woodruff DP, Unterberger W, Noakes TCQ, Bailey P, Ganduglia-Pirovano MV, Sauer J. Surf Sci, 2012, 606: 1716-1727

65 Feiten FE, Kuhlenbeck H, Freund HJ. Phys Chem Chem Phys, 2016, 18: $3124-3130$

66 Ibach H, Mills DL. Electron Energy Loss Spectroscopy and Surface Vibrations. New York: Elsevier Inc., 1982

67 Schlichting H. Dissertation for the Doctoral Degree. Twin Cities: University of Minnesota, 1990

68 Schlichting H, Menzel D. Rev Sci Instrum, 1993, 64: 2013-2022

69 Skorodumova NV, Simak SI, Lundqvist BI, Abrikosov IA, Johansson B. Phys Rev Lett, 2002, 89: 166601

70 Pfau A, Schierbaum KD. Surf Sci, 1994, 321: 71-80

71 Bagus PS, Nelin CJ, Ilton ES, Baron M, Abbott H, Primorac E, Kuhlenbeck H, Shaikhutdinov S, Freund HJ. Chem Phys Lett, 2010, 487: $237-240$

72 Esch F, Fabris S, Zhou L, Montini T, Africh C, Fornasiero P, Comelli G, Rosei R. Science, 2005, 309: 752-755

73 Torbrügge S, Reichling M, Ishiyama A, Morita S, Custance O. Phys Rev Lett, 2007, 99: 056101

74 Jerratsch JF, Shao X, Nilius N, Freund HJ, Popa C, Ganduglia-Pirovano MV, Burow AM, Sauer J. Phys Rev Lett, 2011, 106: 246801

75 Zallen R. The Physics of Amorphous Solids. Weinheim: Wiley-VCH Verlag $\mathrm{GmbH}, 2004$

76 Zachariasen WH. J Am Chem Soc, 1932, 54: 3841-3851

77 Lichtenstein L, Heyde M, Freund HJ. J Phys Chem C, 2012, 116: 20426-20432

78 Büchner C, Heyde M. Prog Surf Sci, 2017, 92: 341-374

79 McFarland EW, Metiu H. Chem Rev, 2013, 113: 4391-4427

80 Robertson J, Clark SJ. Phys Rev B, 2011, 83: 075205 
81 Wendt S, Sprunger PT, Lira E, Madsen GKH, Li Z, Hansen JØ, Matthiesen J, Blekinge-Rasmussen A, Laegsgaard E, Hammer B, Besenbacher F. Science, 2008, 320: 1755-1759

82 Stavale F, Nilius N, Freund HJ. New J Phys, 2012, 14: 033006

83 Stavale F, Pascua L, Nilius N, Freund HJ. Phys Rev B, 2012, 86: 085448

84 Shao X, Nilius N, Myrach P, Freund HJ, Martinez U, Prada S, Giordano L, Pacchioni G. Phys Rev B, 2011, 83: 245407

85 Nilius N, Freund HJ. Acc Chem Res, 2015, 48: 1532-1539

86 Cui Y, Nilius N, Freund HJ, Prada S, Giordano L, Pacchioni G. Phys $\operatorname{Rev}$ B, 2013, 88: 205421

87 Zheng H, Weismann A, Berndt R. Phys Rev Lett, 2013, 110: 226101

88 Yulikov M, Sterrer M, Heyde M, Rust HP, Risse T, Freund HJ, Pacchioni G, Scagnelli A. Phys Rev Lett, 2006, 96: 146804

89 Sterrer M, Yulikov M, Risse T, Freund HJ, Carrasco J, Illas F, Di Valentin C, Giordano L, Pacchioni G. Angew Chem Int Ed, 2006, 45: 2633-2635

90 Pacchioni G, Giordano L, Baistrocchi M. Phys Rev Lett, 2005, 94: 226104

91 Giordano L, Pacchioni G. Phys Chem Chem Phys, 2006, 8: 33353341

92 Frondelius P, Hellman A, Honkala K, Häkkinen H, Grönbeck H. Phys Rev B, 2008, 78: 085426

93 Giordano L, Cinquini F, Pacchioni G. Phys Rev B, 2005, 73: 045414

94 Goniakowski J, Noguera C. Interface Sci, 2004, 12: 93-103

95 Grönbeck H. J Phys Chem B, 2006, 110: 11977-11981

96 Sterrer M, Risse T, Heyde M, Rust HP, Freund HJ. Phys Rev Lett, 2007, 98: 206103

97 Tersoff J, Hamann DR. Phys Rev B, 1985, 31: 805-813

98 Sterrer M, Risse T, Martinez Pozzoni U, Giordano L, Heyde M, Rust HP, Pacchioni G, Freund HJ. Phys Rev Lett, 2007, 98: 096107

99 Repp J, Meyer G, Olsson FE, Persson M. Science, 2004, 305: 493495

100 Honkala K, Häkkinen H. J Phys Chem C, 2007, 111: 4319-4327

101 Hellman A, Klacar S, Gronbeck H. J Am Chem Soc, 2009, 131: 16636-16637

102 Frondelius P, Häkkinen H, Honkala K. Phys Chem Chem Phys, 2010, 12: $1483-1492$

103 Chiesa M, Giamello E, Paganini MC, Sojka Z, Murphy DM. J Chem Phys, 2002, 116: 4266-4274

104 Pacchioni G, Ferrari AM, Giamello E. Chem Phys Lett, 1996, 255: $58-64$

105 Sterrer M, Diwald O, Knözinger E. J Phys Chem B, 2000, 104: 3601-3607

106 Li Z, Werner K, Qian K, You R, Płucienik A, Jia A, Wu L, Zhang L, Pan H, Kuhlenbeck H, Shaikhutdinov S, Huang W, Freund HJ. Angew Chem Int Ed, 2019, 58: 14686-14693

107 Vilé G, Bridier B, Wichert J, Pérez-Ramírez J. Angew Chem Int Ed, 2012, 51: 8620-8623

108 García-Melchor M, Bellarosa L, López N. ACS Catal, 2014, 4: 40154020

109 Fernández-Torre D, Carrasco J, Ganduglia-Pirovano MV, Pérez R. $J$ Chem Phys, 2014, 141: 014703

110 Negreiros FR, Camellone MF, Fabris S. J Phys Chem C, 2015, 119: $21567-21573$

111 García-Melchor M, López N. J Phys Chem C, 2014, 118: 1092110926

112 Huang ZQ, Liu LP, Qi S, Zhang S, Qu Y, Chang CR. ACS Catal, 2018, 8: 546-554

113 Nilius N, Ganduglia-Pirovano MV, Brázdová V, Kulawik M, Sauer J, Freund HJ. Phys Rev Lett, 2008, 100: 096802

114 Schneider WD, Heyde M, Freund HJ. Chem Eur J, 2018, 24: $2317-$ 2327

115 Ricci D, Bongiorno A, Pacchioni G, Landman U. Phys Rev Lett, 2006, 97: 036106

116 Bäumer M, Freund HJ. Prog Surf Sci, 1999, 61: 127-198

117 Henry CR. Surf Sci Rep, 1998, 31: 231-325
118 Lin X, Nilius N, Freund HJ, Walter M, Frondelius P, Honkala K, Häkkinen H. Phys Rev Lett, 2009, 102: 206801

119 Lin X, Nilius N, Sterrer M, Koskinen P, Häkkinen H, Freund HJ. Phys Rev B, 2010, 81: 153406

120 Bollinger MV, Lauritsen JV, Jacobsen KW, Nørskov JK, Helveg S, Besenbacher F. Phys Rev Lett, 2001, 87: 196803

121 Shao X, Prada S, Giordano L, Pacchioni G, Nilius N, Freund HJ. Angew Chem Int Ed, 2011, 50: 11525-11527

122 Prada S, Giordano L, Pacchioni G. J Phys Chem C, 2013, 117: 99439951

123 Stavale F, Shao X, Nilius N, Freund HJ, Prada S, Giordano L, Pacchioni G. J Am Chem Soc, 2012, 134: 11380-11383

124 Pacchioni G, Ricart JM, Illas F. J Am Chem Soc, 1994, 116: 1015210158

125 Hansen KH, Worren T, Stempel S, Lægsgaard E, Bäumer M, Freund HJ, Besenbacher F, Stensgaard I. Phys Rev Lett, 1999, 83: 41204123

126 Wilde M, Fukutani K, Naschitzki M, Freund HJ. Phys Rev B, 2008, 77: 113412

127 Viñes F, Loschen C, Illas F, Neyman KM. J Catal, 2009, 266: 59-63

128 Wilde M, Fukutani K, Ludwig W, Brandt B, Fischer JH, Schauermann S, Freund HJ. Angew Chem Int Ed, 2008, 47: 9289-9293

129 Doyle AM, Shaikhutdinov SK, Jackson SD, Freund HJ. Angew Chem Int Ed, 2003, 42: 5240-5243

130 Ludwig W, Savara A, Dostert KH, Schauermann S. J Catal, 2011, 284: $148-156$

131 Neyman KM, Schauermann S. Angew Chem Int Ed, 2010, 49: 47434746

132 Ludwig W, Savara A, Madix RJ, Schauermann S, Freund HJ. J Phys Chem C, 2012, 116: 3539-3544

133 Schauermann S, Freund HJ. Acc Chem Res, 2015, 48: 2775-2782

134 Calaza F, Stiehler C, Fujimori Y, Sterrer M, Beeg S, Ruiz-Oses M, Nilius N, Heyde M, Parviainen T, Honkala K, Häkkinen H, Freund HJ. Angew Chem Int Ed, 2015, 54: 12484-12487

135 Tauster SJ. Acc Chem Res, 1987, 20: 389-394

136 Vurens GH, Salmeron M, Somorjai GA. Surf Sci, 1988, 201: 129144

137 Sun YN, Qin ZH, Lewandowski M, Carrasco E, Sterrer M, Shaikhutdinov S, Freund HJ. J Catal, 2009, 266: 359-368

138 Sun YN, Giordano L, Goniakowski J, Lewandowski M, Qin ZH, Noguera C, Shaikhutdinov S, Pacchioni G, Freund HJ. Angew Chem Int Ed, 2010, 49: 4418-4421

139 Giordano L, Lewandowski M, Groot IMN, Sun YN, Goniakowski J, Noguera C, Shaikhutdinov S, Pacchioni G, Freund HJ. J Phys Chem C, 2010, 114: 21504-21509

140 Merte LR, Bai Y, Zeuthen H, Peng G, Lammich L, Besenbacher F, Mavrikakis M, Wendt S. Surf Sci, 2016, 652: 261-268

141 Fu Q, Li WX, Yao Y, Liu H, Su HY, Ma D, Gu XK, Chen L, Wang Z, Zhang H, Wang B, Bao X. Science, 2010, 328: 1141-1144

142 Zhang K, Li L, Shaikhutdinov S, Freund HJ. Angew Chem Int Ed, 2018, 57: 1261-1265

143 Pan Q, Weng X, Chen M, Giordano L, Pacchioni G, Noguera C, Goniakowski J, Shaikhutdinov S, Freund HJ. ChemCatChem, 2015, 7: $2620-2627$

144 Wang HF, Ariga H, Dowler R, Sterrer M, Freund HJ. J Catal, 2012, 286: $1-5$

145 Wang HF, Kaden WE, Dowler R, Sterrer M, Freund HJ. Phys Chem Chem Phys, 2012, 14: 11525-11533

146 Sterrer M, Freund HJ. Catal Lett, 2013, 143: 375-385

147 Prieto MJ, Klemm HW, Xiong F, Gottlob DM, Menzel D, Schmidt T, Freund HJ. Angew Chem Int Ed, 2018, 57: 8749-8753

148 Fu Q, Bao X. Chem Soc Rev, 2017, 46: 1842-1874

149 Miners SA, Rance GA, Khlobystov AN. Chem Commun, 2013, 49: 5586-5588

150 Koch MH, Jakob P, Menzel D. Surf Sci, 1996, 367: 293-306

151 Levenspiel O. Chemical Reaction Engineering. 3rd ed. New York: John Wiley \& Sons, 1999 